\title{
An Optimal Foraging-Based Model of Hunter-Gatherer Population Dynamics
}

\author{
GARY E. Belovsky \\ Department of Biology and School of Natural Resources, University of Michigan, \\ Ann Arbor, Michigan, 48109-1115
}

Received May 23, 1988

\begin{abstract}
Population changes for hunter-gatherers are modeled on the basis of nutritional intake, which is determined using an optimal foraging model based upon the optimization technique of linear programming. The population model not only demonstrates how hunter-gatherer demography changes with nutrition, but also shows how their density influences food abundance in the environment which in turn affects their nutritional status. Differences in food availability in different environments can be assessed by examining the effects of different preexploitation maxima for food abundances. Hunter-gatherer populations are predicted by the model to display a stable limit cycle which varies in severity with the maximum food abundance in the environment, being more severe at very low and high food abundances. Observed hunter-gatherer densities, growth rates, and life expectancies are shown to be consistent with the population model's predictions for different environments. The model is also used to examine the impact huntergatherers might have on their food resources including whether or not overexploitation (extinction) occurs and how their diets change in different environments with changes in population density. Finally, the model is used to examine archaeological questions about the Paleo-Indian colonization of the New World and the effects of technological innovation by hunter-gatherers. 1988 Academic Press, Inc.
\end{abstract}

\section{INTRODUCTION}

Optimal foraging models developed in behavioral ecology have been employed to examine diet selection by human hunter-gatherers with varying degrees of predictive success (see Belovsky 1987, and references therein). The underlying assumption of foraging ecology is that either the nutritional status of an individual determines his/her fitness (survival and reproduction) or the time needed to acquire his/her necessary nutritional requirements determines fitness. In the first case, greater nutritional intake leads to higher fitness, and in the latter case greater time foraging leads to lower fitness because of increased exposure to deleterious environmental factors or reduced time for other fitness-increasing behaviors (e.g., care of young). The former goal is called nutrient maximization and the latter is time minimization (Belovsky 1987). 
The original rationale in animal ecology for using these models was to gain insights into how animals perceive potential food resources, so that a food-based definition of carrying capacity could be constructed (MacArthur and Pianka 1966; Emlen 1966, Schoener 1969a 1969b, 1971); i.e., the models could be used to make more realistic population assessments. While the study of optimal foraging models has become a major area of research with implications for neurobiology and psychology, the original intent of using these models to understand population-level processes has been largely overlooked (Schoener 1987). Only a few studies have actually built population models around optimal foraging models (Werner 1977, Belovsky 1984a, 1984b, 1986, Winterhalder et al. 1988; Abrams 1984; Comins and Hassell 1979; Hassell and May 1973).

In this paper, I use an optimal foraging model developed explicitly for human hunter-gatherers which employs the optimization technique of linear programming (Belovsky 1987) to construct a hunter-gatherer population model. The foraging model appears to predict the observed hunter-gatherer ingestion of meat and vegetable foods in environments of different primary productivities, based upon a foraging goal which maximizes nutrient intake (Belovsky 1987). The foraging model is used to construct a population model based upon the assumption that nutritional intake limits population growth. Included in the population model are explicit conversions of nutritional intake into birth and death rates and the depletion of animal and plant populations by exploitation.

A foraging-based population model for hunter-gatherers can be very useful to anthropologists and archaeologists as a means of constructing and testing hypotheses about the role subsistence plays in human population dynamics and the dynamics of their food populations. For example, some demographers argue that human hunter-gatherer populations are maintained at densities well below the "carrying capacity" of the environment, where "carrying capacity" is defined as the total amount of food that the environment can provide divided by per capita human requirements (see Hassan 1981, and references therein). From many of these analyses, the conclusion is that hunter-gatherer densities are maintained below computed maximum densities ("carrying capacities") and cultural means such as infanticide, abortion, and birth control (e.g., Hassan 1981; Glassow 1978) are invoked to explain their observations.

The above definition of "carrying capacity" is an obsolete usage which has largely been abandoned in ecological studies, since it does not include the feedback between consumer populations and their food populations. All food in the environment cannot be consumed without decreasing its recovery rate or decreasing the ability of the consumer to harvest it in the available feeding time (also see Winterhalder et al. 1988). Consequently, a more realistic definition of carrying capacity might indicate that 
hunter-gatherers are ultimately food limited and cultural means of reducing population size may represent proximate manifestations of an ultimate food limit.

Also, a population model based upon hunter-gatherer foraging models might enable us to assess more fully the "overkill" hypothesis for megafaunal extinction at the end of the Pleistocene by more thoroughly examining human population expansion into new environments such as the New World and Australia (Martin 1966, 1967, 1973, 1982, 1984; Mosimann and Martin 1975; Budyko 1967, 1974; Haynes 1982; Whittington and Dyke 1984). In other words, under what conditions might huntergatherers deplete their food populations to extinction?

To demonstrate the applicability of the model for hunter-gatherer populations, their observed population dynamics will be shown to be consistent with the model's predictions for environments differing in primary productivity. The model will then be used to examine the severity of exploitation of food resources by hunter-gatherers and the archaeological consequences of their colonization of new areas. Furthermore, the models employed to argue for megafaunal "overkill" will be shown to be biologically unrealistic and structurally unstable in comparison to the model developed here. These preliminary uses of the model, I hope, will indicate its utility for further investigations.

\section{MODEL CONSTRUCTION}

\section{The Diet Model}

The hunter-gatherer population model presented here is constructed around a linear programming model for diet choice, where the foraging goal is nutrient maximization (maximum energy and/or protein intake). The foraging model's structure, assumptions, and verification are presented in a previous paper (Belovsky 1987). However, to summarize, the model employs three constraints to hunter-gatherer diet choice:

(1) the amount of each type of food that people can digest given their digestive tract's capacity, the turnover rate of different foods through the digestive tract, and the amount of the digestive tract filled by a unit intake of each food;

(2) the amount of each type of food that people can harvest in some foraging period (e.g., day) which is set by climatic and physiological limits to activity, and the rate at which each food can be harvested given its abundance as well as the time required to prepare it for consumption and make tools to harvest it; and

(3) the amount of each food type that must be ingested by people to 
satisfy their physiological demands for protein and energy, given the digestible protein and energy content of each food.

Given the above constraints, the combination of food types that best satisfies the nutrient-maximizing or time-minimizing goals can be predicted. From my previous work, hunter-gatherers appear to be nutrient maximizers when two food types are used to define their diets: meat (hunted) and vegetable (gathered) foods. The model is constructed to predict the diet of an average adult in the population (a hypothetical individual doing both male and female work in proportion to each sex's frequency in the population; this accounts for sexual division of labor) and his/her dependents (Belovsky 1987). A graphical analysis of this model is presented in Fig. 1; however, the model is fully described else-

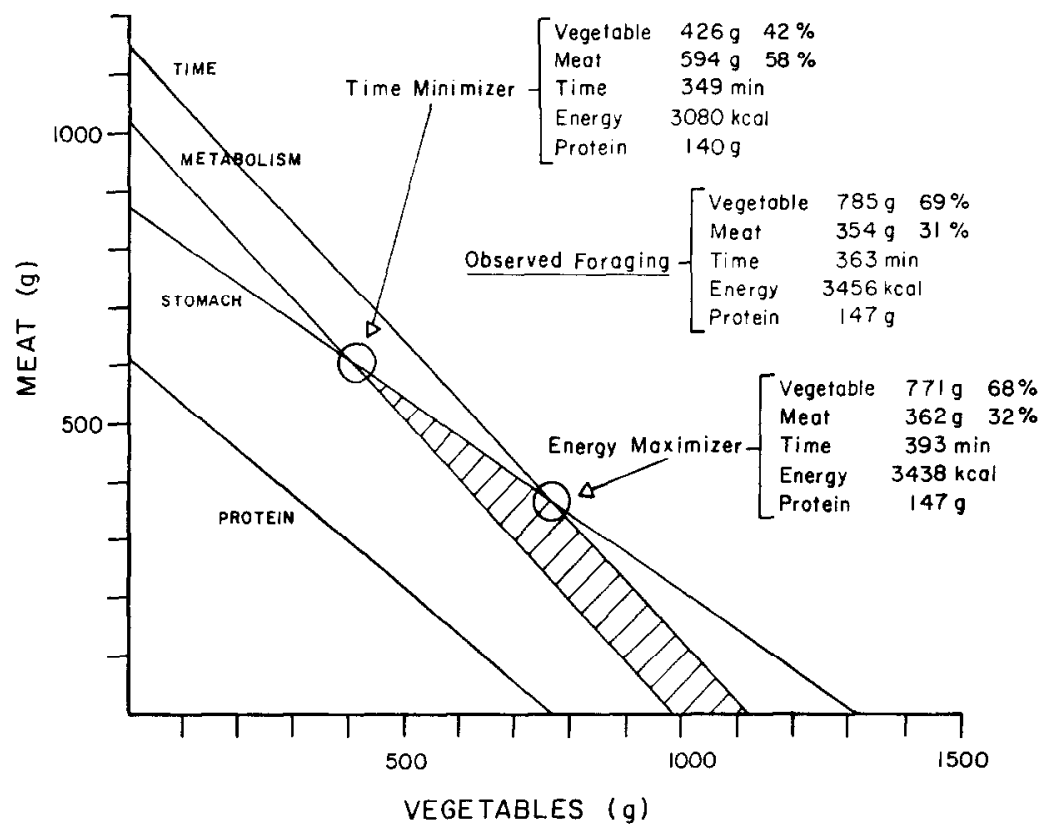

FIG. 1. This example of a linear programming diet model for the !Kung San is taken from Belovsky (1987: Fig. 2). The feeding time (time line), digestive (stomach line), energy (metabolism line), and protein requirement constraints are presented. The cross-hatched region represents the feasible diet combinations of gathered (vegetable) and hunted (meat) foods that satisfy the constraints. The solutions that maximize nutritional intake (energy maximizer) and minimize feeding time (time minimizer) are presented and compared with the observed foraging behavior of these hunter-gatherers. The nutrition-maximizing solution is not statistically different from the observed diet, but the time-minimized solution is (Belovsky 1987). This is the observed pattern for a number of modern hunter-gatherers (Belovsky 1987). 
where (Belovsky 1987). This model for human foraging is more appropriate than other optimal foraging models (Belovsky 1987), since it can explicitly include in the constraints:

(1) physiological and behavioral limits to activities,

(2) different environmental conditions (e.g., climate, food abundances),

(3) differences in the spatial distributions of plant and animal foods (Belovsky et al. 1989), and

(4) different methods needed to hunt and gather.

These variations on the model's parameter values can be used to examine the trade-offs that people must confront in making diet choices in different environments.

\section{The Population Model}

The solution for the optimal diet can be readily converted into nutritional intake for individuals in a population and, given the hunter-gatherer population size, the diet prediction can be converted into depletion of plant and animal food populations. The human, plant, and animal population densities will then provide feedback to the diet model through changes in the foraging constraint parameters.

The manner in which the diet model changes with changing human, plant, and animal populations is presented graphically in Fig. 2. The paper presenting the diet model (Belovsky 1987) provides the necessary constraint parameters and how they change given changes in human, plant, and animal population densities discussed below.

The densities of the animal and/or plant populations impact on only one foraging constraint, the feeding time constraint, by moving it upward (Fig. 2A) as more food is available. This occurs because the time needed to crop foods diminishes as more food is available (see below).

Changes in the human population, caused by changes in the number of dependents per foraging adult in the group and/or total density, act in several ways on the foraging model. As the number of dependents per foraging adult increases, the digestive and energy/protein requirements increase to reflect the added digestive capacity provided by the dependents and their added nutritional requirements (Fig. 2B: see Belovsky 1987). In addition, the feeding time constraint moves upward since the dependents aid the foraging adults with some of the food acquisition or preparation, effectively increasing the amount of food cropped per unit time by the adult (Fig. 2B: see Belovsky 1987). As the human population density increases only one constraint is modified, feeding time, which 

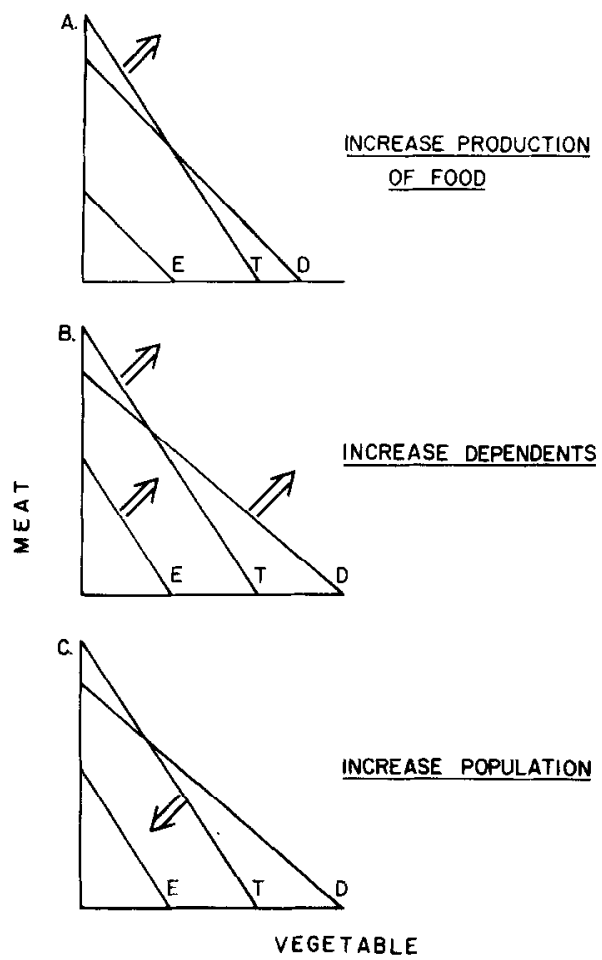

FIG. 2. This figure presents how changes in the population model affect the linear programming diet model's constraint equations. The arrows refer to the expected directional changes in constraint equations with population changes. $E$ is the energy requirement constraint, $T$ is the feeding time constraint, and $D$ is the digestive capacity constraint.

moves downward because greater human densities lead to depletion of food populations, requiring more time for humans to acquire a unit of food (Fig. 2C: see below).

\section{Converting Diet Into Nutrition}

The optimal foraging model's solution provides an estimate for the intake of meat and vegetable foods measured in mass per unit time (grams dry weight per day) provided by each average foraging adult for consumption by the adult and his/her dependents. It is very easy to convert these values into nutrition per adult forager. The consumption of each food is multiplied by its nutritional value which is already included in the nutritional (protein and energy) constraints (Belovsky 1987) and these products for each food are then summed. The important aspect of nutritional status is not the amount ingested but the amount ingested above the 
nutritional requirements of the forager and his/her dependents (total intake - requirements). If this value is positive, a surplus is indicated and it can be used for reproduction, while if the value is negative, a shortfall is indicated and it must be eliminated by mortality.

Previous work with the foraging model indicated that the nutritional maximization goals of protein or energy maximization were interchangeable (Belovsky 1987). Therefore, for simplicity the optimal diet model was assumed to include a single nutritional constraint, energy. This makes the population model, including the diet choice model, more tractable.

\section{Converting Nutrition into Births and Deaths}

Conversion of nutritional surpluses or shortfalls into births and deaths is not difficult but one must be careful how this is accomplished so population changes are correctly reflected. The correct way to incorporate nutritional intake into a population model requires two parameters (Schoener 1973):

(1) the nutritional requirements of the foragers for maintaining their own body functions plus those of any dependents (survival requirement: $M$ ), and

(2) the nutritional requirement to produce a new offspring (reproductive requirement: $R$ ), who will be added to the dependents that an individual will be caring for in future time periods.

For humans, $M$ is a measure of the physiological requirements (maintenance metabolism, protein daily allowance, etc.) for the adult plus the requirements for dependents (number of dependents multiplied by $R$ ). $R$ represents those nutritional requirements that a parent must supply to each child to enable it to survive from conception to independence; these are averaged over the time period being addressed by the model (e.g., day).

If we assume that children begin to help forage at 13 years of age after 12 years of dependence, during which time they provided only occasional aid in foraging (Hassan 1981; Howell 1976, 1979; Lee 1979), then in a population with a stable age distribution the proportion of children becoming independent (actively foraging) each year would be 1/12. Independence only refers to foraging, not reproductive maturity. If the maximum age for an individual is estimated to be 60 years, where the survivorship curve begins to drop precipitously (Hassan 1981; Howell 1976, 1979), then in a population with a stable age distribution the proportion of adults dying from senescence each year would be $1 /(60-12)$. The assump- 
tion of a stable age distribution is very robust, having little effect upon the population model's predictions.

$M$ is defined as $M_{\mathrm{A}}+R\left(C / A_{t}\right)$, where $M_{\mathrm{A}}$ is the adult nutritional requirement and $R\left(C_{t} / A_{t}\right)$ is the nutritional requirement for dependents. $A_{t}$ is the number of adults at time $t$ and $C_{t}$ is the number of children at time $t$. The value for $M_{\mathrm{A}}$, adult energy requirement, is $2190 \mathrm{kcal} / \mathrm{day}$; this requirement includes the nutritional needs of the adult $(1862 \mathrm{kcal} / \mathrm{day}$ : see studies reviewed in Belovsky 1978; Frisancho 1981) plus a sufficient nutritional intake to ensure that an adult living to senescence would leave one surviving offspring (replacement reproduction: $328 \mathrm{kcal} /$ day $=12$ years of dependence $\times R /(60$ years to senescence -12 years of dependence) ) (Schoener 1973). The nutritional requirements for dependents $(R)$ is $1312 \mathrm{kcal} / \mathrm{day}$, which is an average for children from conception until 13 years of age (Belovsky 1987; Hassan 1981; Frisancho 1981).

Combining the two measures of nutritional requirements $(M$ and $R)$ with the nutritional intake $(I)$ and the proportions of children becoming adults and adults dying from senescence, the change in the huntergatherer population density can be written as:

$$
\begin{aligned}
& A_{t+1}=C_{t} / 12+A_{t}(1-1 /(60-12)), \quad \text { for } I \geqslant M, \\
& C_{t+1}=C_{t}(1-1 / 12)+A_{t+1}((I-M) / R)
\end{aligned}
$$

and

$$
\begin{aligned}
& A_{t+1}=A_{t}(I / M)(1-1 /(60-12)), \quad \text { for } I<M, \\
& C_{t+1}=C_{t}(I / M)(1-1 / 12),
\end{aligned}
$$

Since there is an upper limit to the number of children under 3 years of age (Blurton Jones and Sibley 1978) that a hunter-gatherer woman can carry while she is working, this was accounted for in the model by never permitting more than 0.6 children per adult in the population. This restriction and senescence were the only nonnutritional limits placed on population dynamics, and the limit to carrying young was found to enter into the model's solution only for environments with the highest productivity (see below).

\section{The Hunter-Gatherer's Food Environment}

In the original development of the optimal foraging model for huntergatherers (Belovsky 1987), the cropping rates for gathered and hunted foods were expressed as functions of environmental primary productivity. These cropping rate relationships are presented in Fig. 3. While these relationships were adequate to address how diet choice might change in different global environments (Belovsky 1987), a population model re- 


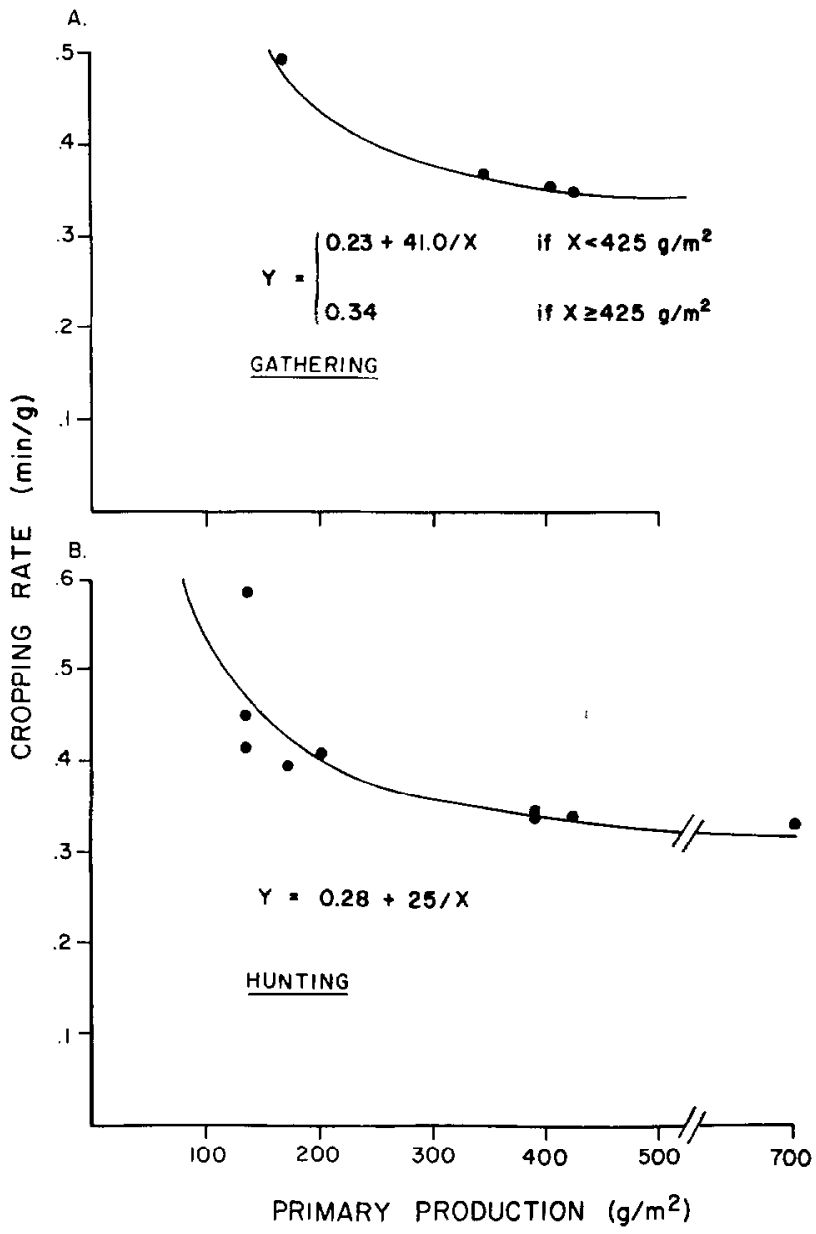

FIG. 3. The observed relationship between the primary productivity in different environments and the cropping rates of hunter-gatherers for gathered $(A)$ and hunted $(B)$ foods is presented (Belovsky 1987). The primary productivity in these plots represents total harvestable production of nonstructural components of the vegetation within $3 \mathrm{~m}$ of the ground, so that it would be within reach of humans or their prey animals.

quires inputs on how the food resources are depleted by human utilization, how they recover from exploitation, and what the effects of depletion are on hunter-gatherer cropping rates. Since the diet model examines the consumption of two food types (hunted and gathered foods), how the foraging time constraints might change beyond that discussed in the original paper (Belovsky 1987) will be presented below for each food separately.

Gathered foods (vegetable foods) are the easiest to incorporate in the 
model since they are a direct function of primary productivity. Most vegetable foods for humans are fruits, tubers, and seeds; these plant parts average about $2 \%$ of total primary productivity (Minnis 1985; Harper 1977; McNaughton and Wolfe 1973). Since the original cropping rate function (Belovsky 1987) for gathered foods was based on total primary productivity, the relationship in Fig. 3 was modified to include only the production of fruits, seeds, and tubers, $2 \%$ of total production. Furthermore, on average, plants are able to replace losses due to consumption at a rate 0.22 times the remaining plants per annum (Harper 1977).

With the above information a logistic equation for fruit, seed, and tuber availability at time $t+1\left(P_{t+1}\right)$ can be written as

$$
P_{t+1}=S_{t}+0.22 S_{t}\left(\left(K_{\mathrm{P}}-S_{t}\right) / K_{\mathrm{P}}\right)
$$

and

$$
S_{t}=\left(P_{t}-\mathrm{G}_{\mathrm{P}}-0.10 H_{t}\right),
$$

where $0.10 H_{t}$ is the consumption of plant parts by animals of $H$ biomass at time $t$ for plant parts that are also used by people (Farlow 1976), $K_{\mathrm{P}}$ is the maximum environmental production of seeds, fruit, and tubers, and $\mathrm{G}_{\mathrm{P}}$ is the quantity of plant food harvested by humans. $K_{\mathrm{P}}$ is 0.02 times the maximum environmental primary productivity $(P) . G_{\mathrm{P}}$ can be written as

$$
G_{\mathrm{P}}=365 A_{t}(4.2)\left(I_{\mathrm{P}, t}\right) / 10^{8},
$$

where 4.2 is a conversion factor relating the mass of plants harvested to acquire a unit of plant food ingested (Lee 1979; Hawkes et al. 1982), $I_{\mathrm{P}, t}$ is the quantity of ingested plant food provided by each forager (adult) at time period $t$ predicted from the foraging model, 365 converts daily consumption to annual consumption, and $10^{8}$ converts human consumption into the appropriate units to compare with primary production (grams dry weight per year per $100 \mathrm{~km}^{2}$ into grams dry weight per year per $\mathrm{m}^{2}$ ).

The seeds, fruits, tubers, etc., eaten by people cannot be totally eliminated from the environment, unlike the hunted animals, because the plant itself is not eliminated by human consumption, guaranteeing recovery (sensu Caughley and Lawton 1981, noninteractive-reactive herbivory). Therefore, the plant biomass used by people was never allowed to fall below 0.0043 times maximum environmental primary productivity $(0.02$ edible plant parts $\times 0.22$ plant biomass replaced each time period $\times 0.98$ inedible plant parts).

Hunted food (meat) cannot be included in the population model as easily, since the populations of animal prey will be a function of human exploitation and plant primary productivity. If we restrict hunting to larger species of mammals $(>10 \mathrm{~kg})$, ecological studies demonstrate that 
the maximum environmental biomass of these prey animals is a function of plant primary productivity (Fig. 4B); however, hunting success will vary with the abundance of prey, not its maximum potential abundance. Since the cropping rates for meat were originally developed as a relationship with plant primary productivity (Fig. 3) (Belovsky 1987), it is necessary to express these cropping rates in terms of prey biomass rather than plant primary productivity. Using the relationship in Fig. 4A, a simple conversion provides the new function for the cropping rate of meat (Fig. 4B).
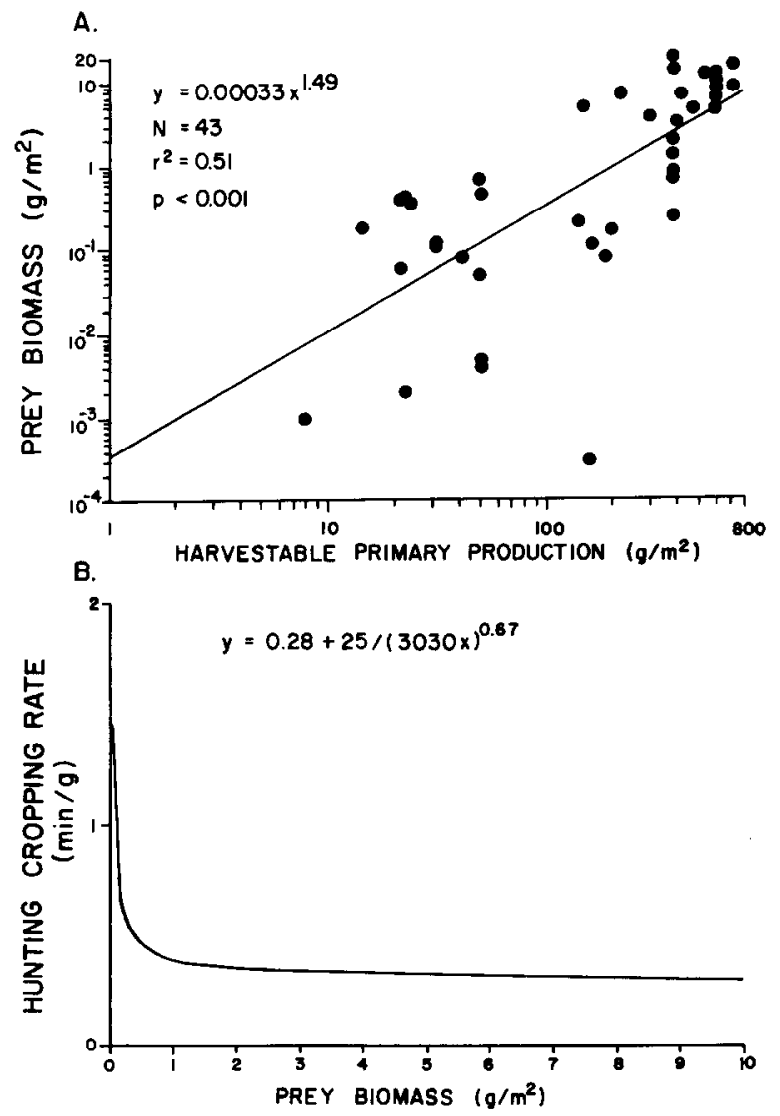

FIG. 4. The relationship between the maximum observed biomass of large prey animals in the environment (>10 kg) and the harvestable primary productivity is presented using data from Farlow (1976) and Belovsky (1986) in Fig. (A). The relationship between the cropping rates for hunted foods in Fig. $3 \mathrm{~B}$ and the biomass of prey animals in the environment is presented in Fig. 4B. This is the relationship used in the population model described in the paper. 
With the above information the availability of animals for hunting at time $t+1$ (biomass: $H_{t+1}$ ) can be written as

$$
H_{t+1}=1.19\left(H_{t}-H_{\mathrm{H}, t}\right),
$$

if $H_{t+1} \leqslant \mathrm{H}$, otherwise

$$
H_{t+1}=H
$$

or

$$
H_{t+1}=0, \quad \text { if } H_{t+1} \text { at any time equals or falls below } 0 .
$$

$\mathrm{H}$ is the maximum animal biomass that can be supported by the available primary production after human consumption of plants,

$$
H=K_{\mathrm{H}}\left(50 K_{\mathrm{P}}-\left(K_{\mathrm{P}}-P_{t+1}\right)\right) / 50 K_{\mathrm{P}},
$$

where $K_{\mathrm{H}}$ is the maximum animal biomass given maximum environmental primary production $\left(50 K_{\mathrm{P}}\right)$ and the relationship in Fig. $4 \mathrm{~A} . H_{\mathrm{H}, t}$ is the harvest of animal biomass by each adult forager at time $t$ and the constant 1.19 is the recovery rate of the animal populations after consumption by predators other than humans (Farlow 1976).

$H_{\mathrm{H}, t}$ can be written as

$$
H_{\mathrm{H}, t}=365 A_{t}(6.7)\left(I_{\mathrm{H}, t}\right) / 10^{8} .
$$

$I_{\mathrm{H}, t}$ is the edible meat provided by each adult forager in the population based on the foraging model. The constant, 6.7 , represents the amount of prey that must be killed to provide a unit of ingested meat, given inedible portions, spoilage, consumption by dogs, etc. (Lee 1979; Budyko 1967, 1974; Martin 1973; Mosimann and Martin 1975); 365 converts daily to annual consumption, and $10^{8}$ converts consumption per $100 \mathrm{~km}^{2}$ to $\mathrm{m}^{2}$.

Environmental primary production is assumed to be the maximum plant production that the environment can provide before human consumption; i.e., it is the annual plant carrying capacity or maximum biomass that can be produced each year in the environment and harvested by humans or their prey. The distinction between total and harvestable primary production is discussed in Belovsky (1987). This distinction is critical in distinguishing between grassland and forest environments, since much of the primary production in a forest cannot be harvested because (1) it is above the reach of humans and/or their prey, and/or (2) the plant structural products are inedible (e.g., wood, bark, etc.). The maximum animal biomass is also set by this plant production prior to human exploitation (Fig. 4A).

As pointed out above, environmental productivity sets upper limits to the human food base. These are not estimates of human carrying capac- 
ity, since hunter-gatherers will deplete the standing crop biomass of foods and reduce the productivity below that which the environment might maximally provide. Therefore, the human carrying capacity, although a function of maximum environmental productivity, will usually be lower than these values imply due to depletion by harvesting.

\section{SOLVING THE FORAGING AND POPULATION MODELS}

The combined foraging and population models are summarized in Fig. 5 as a flowchart, indicating the interplay between variables.

The linear programming foraging model can be solved using the Simplex algorithm (Belovsky 1987). The difficulty of incorporating the foraging behavior model into a population framework involves the large number of times it must be solved, once for each time period (year). Not only must the foraging model be solved, but the changing nutritional effects on population dynamics for each time period (year) must be calculated.

To keep track of the population and foraging parameter changes over time, the model was built into a Lotus 1-2-3 spreadsheet as a large macro. The spreadsheet organizes and keeps track of the parameter changes. The spreadsheet macro requests the input of necessary initial model parameters, accumulates the changes in model parameters over time in a tabular form, and at the conclusion provides the population changes as graphical output. This macro is presented in Appendix I, with a list of all the variables, definitions and equations.

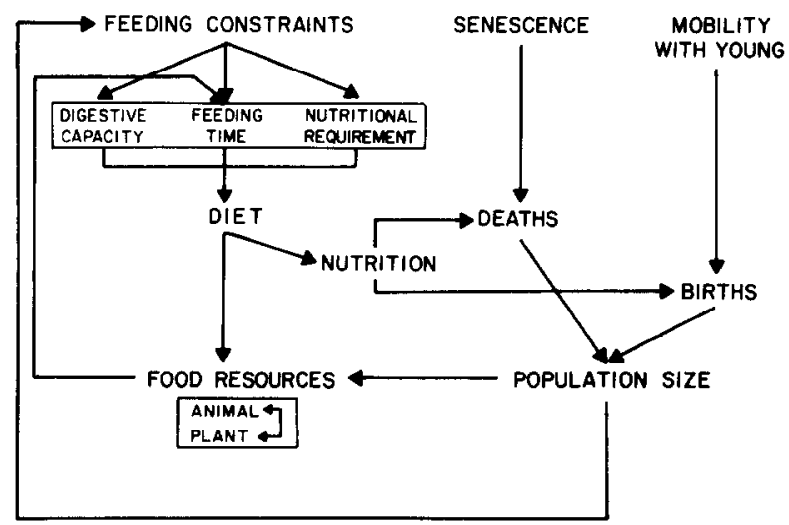

FiG. 5. A flow chart for the population model is presented with the arrows representing the linkages between different aspects of the hunter-gatherer population and food resources. Separate submodels are represented in the chart as boxes: the linear programming foraging model constraints are enclosed in one box, and the plant and animal population dynamics are enclosed in another box. 
The Lotus spreadsheet macro does not include the complete model since it does not solve the linear programming foraging model. The foraging model is solved for the energy-maximizing diet using a second program, What's Best!. What's Best! is a program that solves linear programming problems using the Simplex algorithm within Lotus spreadsheets. The interface between these two programs was automated using a third program, Superkey.

While the biomass of food in the model is expressed in grams per square meter, the human population is presented as individuals $/ 100 \mathrm{~km}^{2}$. The model was started with one adult male-female pair entering a previously unexploited environment (i.e., no other humans are present). Finally, the harvestable primary productivity was assigned within the range observed in nature, $50-800 \mathrm{~g} / \mathrm{m}^{2}$. The model was run for more than 300 iterations (years) and no more than 600 iterations, to determine if and when the population trajectory stabilized. A variety of values for $M, R$, and other model parameters were used to asses the model's sensitivity to changes in parameter values. These parameter changes were restricted to the range reported in the literature.

\section{THE MODEL'S PREDICTIONS}

The model's general characteristics can be examined (Fig. 6) using a harvestable primary productivity of $200 \mathrm{~g} / \mathrm{m}^{2}$ as an example, since this productivity is near the average for the environments that huntergatherers inhabit today. Starting with two adults the population rapidly reaches a maximum per annum growth rate which depends upon attaining a stable age distribution (children/adult: $C_{t} / A_{t}$ ). For a maximum harvest-

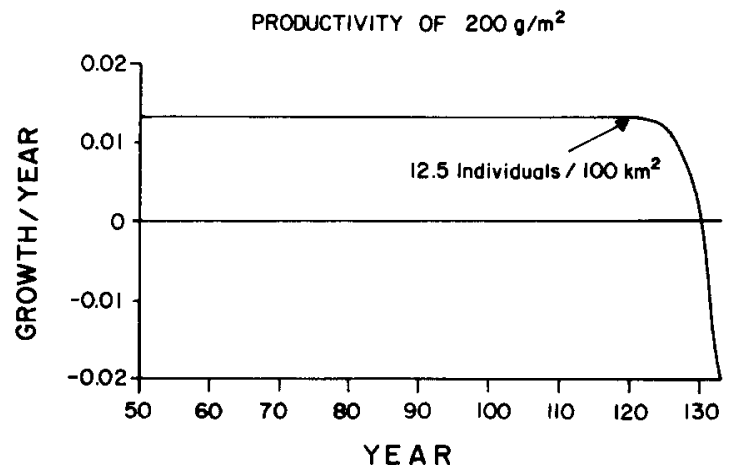

FIG. 6. An example of the model's solution is provided for an environment with a $200 \mathrm{~g} / \mathrm{m}^{2}$ harvestable primary productivity. Changes in the population's growth rate over time are presented. 
able primary productivity of $200 \mathrm{~g} / \mathrm{m}^{2}$, the maximum growth rate is approximately $1.3 \%$ per annum which doubles the population every 53 years. When the population reaches a density of 12.5 individuals $/ 100 \mathrm{~km}^{2}$ (including children), the growth rate begins to decline and eventually falls below zero, indicating that the population is declining (Fig. 6).

If the population is examined over a longer time period (Fig. 7B), it goes through periods of repeated increases and declines which are called stable limit cycles. Stable limit cycles are population trajectories that if perturbed (e.g., artificially increased or decreased), will return to the same trajectory they were following before the perturbation. The period of these cycles (time between successive peaks) is approximately 90 years (Fig. 7B).

Even though population growth rates, the time before first population decline, and the period between subsequent population cycles vary with model parameters, a general pattern of hunter-gatherer stable limit cycles emerges (Figs 7A-7D). Therefore, using a foraging model shown to predict hunter-gatherer diets (Belovsky 1987) and observed nutritional and

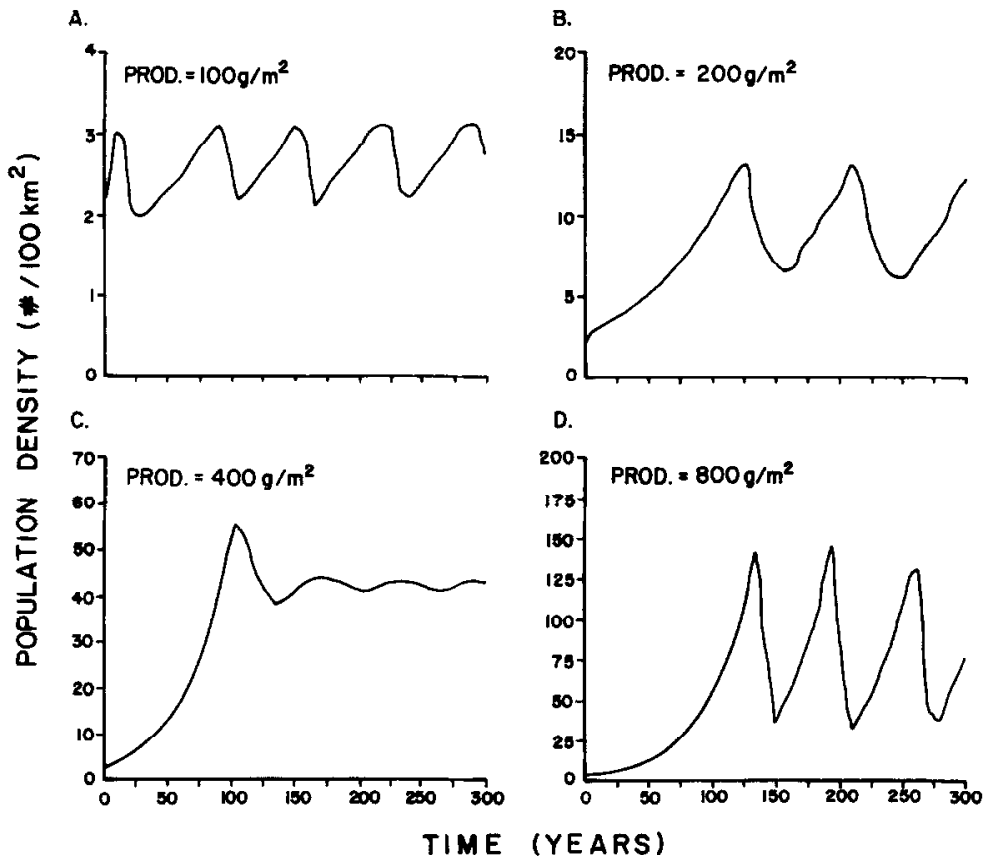

FIG. 7. The population trajectories emerging at four different harvestable primary productivities are presented: $100 \mathrm{~g} / \mathrm{m}^{2}(\mathrm{~A}), 200 \mathrm{~g} / \mathrm{m}^{2}(B), 400 \mathrm{~g} / \mathrm{m}^{2}(C)$, and $800 \mathrm{~g} / \mathrm{m}^{2}$ (D). In all cases a stable limit cycle emerges; however, the severity of this limit cycle, as measured by the ratio of peaks to lows and the length of the period between peaks is greater at low and high harvestable primary productivities. 
environmental parameters for these people, a much more restricted range of population dynamics than predicted by Winterhalder et al. (1988) is obtained. The greater specificity of the model presented here also permits comparison of predicted and observed hunter-gatherer demographic parameters.

Before comparing the model's predictions with observed populations, general characteristics of the predicted population dynamics must be examined. Stable limit cycles are found to arise at all primary productivity levels. However, the intensity of the cycles, as measured by the ratio of population peaks to lows and the time between successive peaks in population size, varies with primary productivity (Figs. 7A-7D). First, the limit cycles increase in severity as harvestable primary productivity increases from the lowest values where a population of hunter-gatherers can persist $\left(50-200 \mathrm{~g} / \mathrm{m}^{2}\right)$. However, as productivity continues to increase, limit cycle severity decreases drastically and then once again increases dramatically $\left(200-800 \mathrm{~g} / \mathrm{m}^{2}\right)$.

The changes in stable limit cycle severity depend on two factors: (1) the potential growth rate (predicted maximum) of the hunter-gatherer population, and (2) the predicted optimal diet for these people. If the huntergatherers' potential population growth rate is high, their population can increase rapidly and deplete foods, possibly causing a limit cycle. If the diet can be switched from predominately one food to an alternate when one is depleted, population fluctuations will be reduced even though hunter-gatherer potential population growth rates are high and food depletion periodically occurs.

The least severe limit cycles occur at intermediate primary productivities where hunter-gatherers have a predicted diet more nearly equal in meat and vegetable consumption (Fig. 10), even though their population will have a high potential growth rate. The lowest harvestable primary productivities at which hunter-gatherer populations can persist produce stable limit cycles which are not the most severe, even though a diet composed only of hunted foods is predicted. Here the people have little impact on food abundance (see below) and have a low potential population growth rate. However, more severe oscillations occur at slightly higher productivities and at the highest primary productivities that also have a predicted diet composed primarily of one food. In these environments sufficient primary production occurs to maintain a high potential population growth rate.

The parameter changes that have the greatest effect on the model's predictions are the age at which children are considered to be adults, the adult and child nutritional requirements and the harvestable primary productivity. In the model, the age at which a child becomes an adult is a reference to his/her ability to forage independently, not a reference to 
reproductive ability. Dependents only occasionally help in food preparation and acquisition, while adults are active independent foragers. Changes in this age affect population growth rate and limit cycle periodicity, but have almost no effect on peak and low population densities in the stable limit cycle. By affecting population growth rates, this value determines the minimum harvestable primary productivity that huntergatherers require to maintain a viable population (a positive population size over time).

Changes in adult and child nutritional requirements and harvestable primary productivity affect the population growth rates and the peak and low densities in the stable limit cycles. Decreases in nutritional requirements and/or increases in harvestable primary productivity increase population growth rates, up to the limit set by a woman's ability to carry infants and still work (see above). These same changes also result in greater population densities at peaks and lows in the stable limit cycle. Equal relative increases in harvestable primary productivity and declines in nutritional requirements lead to equivalent changes in population parameters over time.

Greater harvestable primary productivity and lower nutritional requirements do not yield a 1:1 change in population density; i.e., doubling primary productivity does not double the peak or low hunter-gatherer density. This pattern was also predicted by Winterhalder et al.'s (1988) model. Therefore, many of the earlier anthropological and archaeological attempts to determine whether or not human populations are near their environmental carrying capacity were conceptually flawed since they assumed a 1:1 relationship between food abundance and human density (Hassan 1981; Glassow 1978).

The model's sensitivity to other cropping rate changes will be discussed below in relation to the ways hunter-gatherers might adapt to different environments.

\section{Comparing the Model with Hunter-Gatherer Demography}

The model presented here is based on the idea that hunter-gatherer populations are simply a function of nutrition and nutrition depends upon the availability of food. Food availability is modeled as a function of the environment's maximum harvestable primary productivity and the level of exploitation by people. The only factors in the model that are not related to nutrition are the age at senescence, age at independence, and the maximum number of children a woman can carry and still work. Therefore, a correspondence between observed hunter-gatherer demographic parameters and those predicted by the model leaves nutrition as the most parsimonious explanation. This would indicate that cultural ex- 
planations of demography, such as abortion, infanticide, and euthanasia (see below), are proximate regulating factors and hunter-gatherer populations are ultimately limited by their environments, as are most other animals.

Three demographic parameters for hunter-gatherers will be compared with the model's predictions. The first parameter is the average densities of hunter-gatherers observed in environments of different harvestable primary productivities. This is the most important comparison since a failure to find a correspondence would indicate that these human populations are not nutritionally limited. The other two parameters are maximum population growth rates and life expectancy. These two parameters are not as important to the question of what limits hunter-gatherer populations since a population might be limited in its average density by nutrition, while cultural traits might change the population growth rates and life expectancies to reduce population oscillations. For example, the oscillations of the stable limit cycles might be damped leading to a constant density through modified birth and death rates.

Observed hunter-gatherer population densities at different harvestable primary productivities were found using the literature reviews of Hassan (1981) and Hayden (1981) (40 hunter-gatherer groups). The densities for people using marine foods or anadromous fish were not included (14 cases) since the foraging model was not developed using these foods, and estimates of marine productivity are not as easy to derive as productivity estimates for terrestrial environments. The remaining 26 hunter-gatherer peoples were located on a map showing global maximum primary productivities (Leith 1975) and these values were converted into harvestable quantities (Belovsky 1987). The maximum harvestable primary productivity values and the hunter-gatherer densities were compared using linear regression (Fig. 8A), and a highly significant correlation was found $\left(r^{2}\right.$ $=.82, N=26, p<.001)$. Therefore, hunter-gatherer densities are related to food availability.

To examine this relationship more closely, the regression of the model's predited hunter-gatherer densities versus harvestable primary productivities was compared with the regression line for the observed values. The regression line for the model's predictions (Fig. 8A) was not statistically different from the regression line for the observed data (ANOVA: $F=1.14, d f=1$, N.S.; ANCOVA: $F=1.47, d f=1$, N.S.). Furthermore, the model's predictions for average population densities during the stable limit cycles match the observed densities very well $\left(r^{2}=.85, N=\right.$ $26, p<.001$ ), indicating that hunter-gatherers are probably food-limited and the model represents the relationship rather well.

The model's solutions also indicate that the severity of stable limit cycles should increase, then decline precipitously to a minimum, and then 

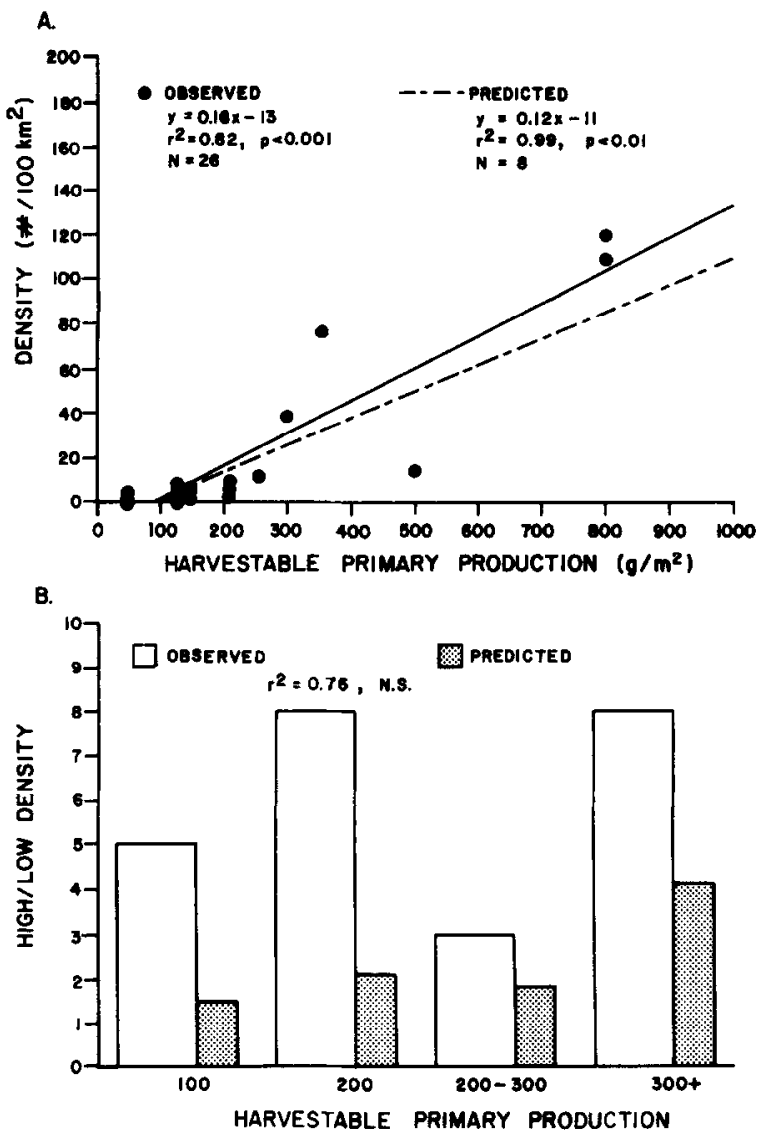

Fig. 8. The observed relationship between the densities of modern hunter-gatherers and their harvestable primary productivity is compared with the model's predicted relationship (A). The observed variation in modern hunter-gatherer densities, ratio of highest to lowest densities reported for environments with comparable primary productivities, but from different studies, are compared with the model's predicted ratio (B). A better comparison could be made if the same hunter-gatherer populations were studied over time, but these data are not available.

increase again as harvestable primary productivity increases (see above). Given the limited population data on hunter-gatherers, this seems to be observed (Fig. 8B). Therefore, the population model, although not predicting exactly the observed hunter-gatherer population trajectories, does portray the general pattern very well.

Observed mortality and growth rates for hunter-gatherers can also be compared with the model's predictions. Reports of hunter-gatherer maximum population growth rates vary between 0.3 and $4 \%$ per annum (Hassan 1975, 1981; Birdsell 1957, 1968; Howell 1979; Angel 1975; Martin 
1973; Mosimann and Martin 1975). The model provides maximum growth rate estimates varying between 0.8 and $2.9 \%$, depending upon harvestable primary productivities increasing as primary productivity increases. Therefore, observed maximum population growth rates and the model's estimates are comparable.

Using data on mortality rates from present day hunter-gatherer populations and skeletal remains from prehistoric Homo sapiens huntergatherers (Hassan 1975, 1981; Wobst 1974; Howcll 1979; Angel 1975; Deevey 1960), the life expectancy for adults can be estimated to be 41.4 \pm 5.5 years $(N=7)$ and $34.1 \pm 4.7$ years $(N=16)$, respectively. The model at different primary productivities provides an average life expectancy of $38.7 \pm 6.6$ years $(N=5)$. This estimate is not significantly different from the observed values (Modern: $t=0.73, d f=9$, N.S.; Prehistoric: $t=1.74, d f=19$, N.S.).

The data on growth and mortality rates further support the idea that hunter-gatherer population dynamics are a function of nutrition, rather than cultural restrictions. This means that these people are limited by their environment in much the same way as any other animal population. While not exactly predicting the demographic parameters, the model does very well; perhaps further additions to the model for the degree of nomadic vs sedentary existence, etc., would explain the observed variations. Nonetheless, the overall agreement between the observed and predicted population densities and parameters raises questions concerning the hunter-gatherers' impacts on food resources.

\section{Hunter-Gatherers' Impacts upon Food Resources}

While the impact of the foraging environment on hunter-gatherer demography has been addressed above, there is a reciprocal question: the human impact on the hunted and gathered foods over time. Traditionally anthropologists and archaeologists have posed this question using two very different perspectives: human destruction of the environment (Martin 1973, 1982, 1984; Mosimann and Martin 1975; Budyko 1967, 1974; Whittington and Dyke 1984) or human cultural traits that prevent overexploitation or lead to maximum sustained yield from the environment (Webster 1981; Webster and Webster 1984; Hames 1987; Hayden 1981). What insights are provided by a population model based upon explicit foraging decisions?

First, the models previously built on the assumption of human overexploitation of foods possess some strange characteristics which have been ignored. It has been claimed that these models provide a stable coexistence between the human populations and their hunted foods with certain parameter values (Martin 1973; Mosimann and Martin 1975; Whittington 
and Dyke 1984), but the characteristics of this coexistence have never been examined. To address this problem, mathematical models must be subjected to a stability analysis which examines the eigenvalues. Eigenvalues provide information on how a population changes when slightly perturbed away from an equilibrium between the interacting populations (May 1973).

A stability analysis of the overexploitation models is presented under Appendix II. Contrary to claims that humans and their prey can achieve stable coexistence in these models with certain parameters, it was found that this equilibrium is unstable and humans will always hunt their prey to extinction. These models are even more unstable than suggested by the eigenvalues. The stability analysis was conducted using differential equations (continuous changes over time) while the original models used difference equations (changes over discrete time) which are inherently less stable (May 1973).

The main reason for this instability is that none of the overexploitation models set the human population's growth rate or equilibrium density (carrying capacity) as functions of prey availability. Therefore, all of these models are constructed without a direct feedback between human demography and food resources. Even by varying hunting success with prey abundance (Mosimann and Martin 1975), these models cannot provide coexistence between humans and their prey.

On the other hand, the model presented here is too complex to allow a stability analysis using eigenvalues. The simulations, however, show that the model can provide stable coexistence or overexploitation depending upon the parameter values (Fig. 9). Similar results have been provided by a human population model based upon a different foraging model (Winterhalder et al. 1988). The potential for stable coexistence in these models depends upon the direct linkage between human demography and food availability.

The model presented here will be used to examine under what conditions hunter-gatherers overexploit their gathered and hunted foods. Changes in the abundances of hunted and gathered foods for environments of different primary productivities are presented in Fig. 9. Two results are surprising (Fig. 9):

(1) at low harvestable primary productivities, hunter-gatherers reduce their hunted food populations but do not cause their extinction, and the hunter-gatherers have no effect upon their gathered foods; and

(2) at high harvestable primary productivities, hunter-gatherers cause the extinction of their hunted foods and reduce the abundance of the gathered foods.

The key to the overexploitation and extinction of hunted foods is the abundance of gathered foods. A greater abundance of gathered foods 


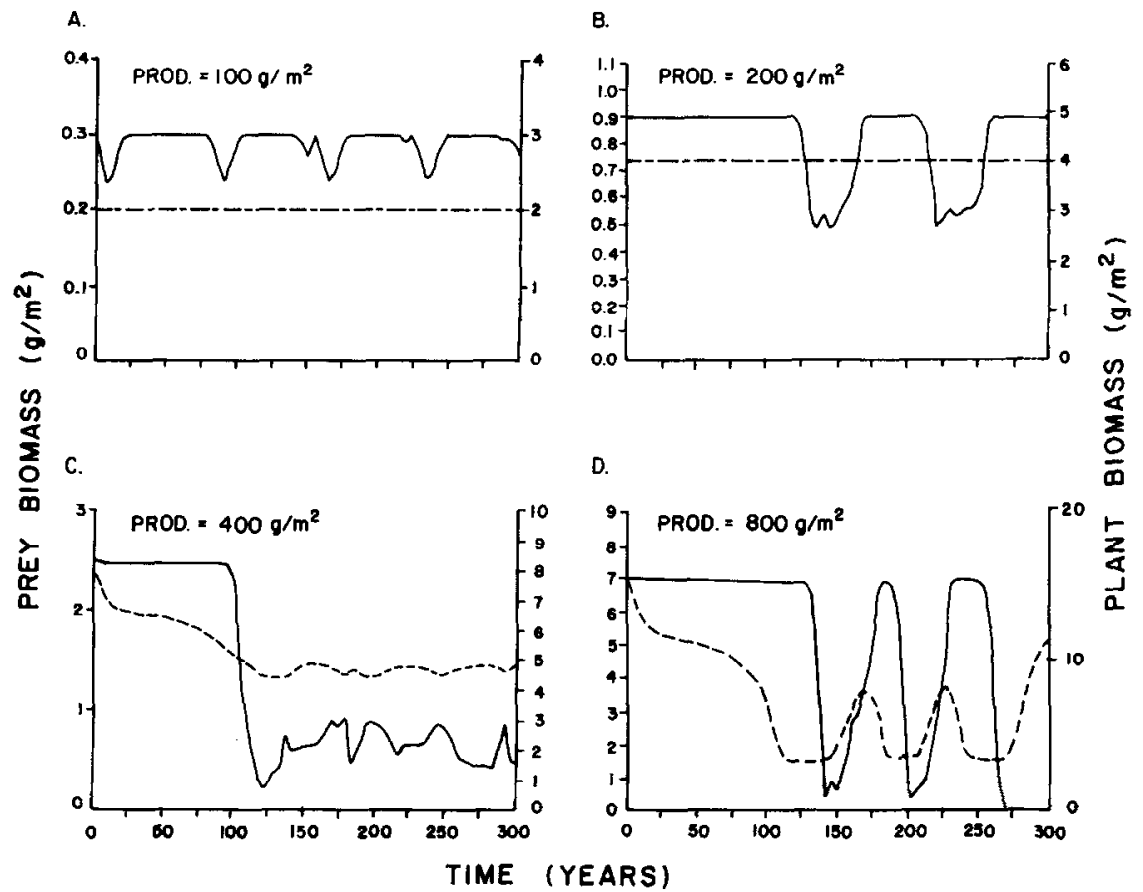

FIG. 9. The model's predictions for changes in hunted and gathered food abundances over time for different harvestable primary productivities are presented: $100 \mathrm{~g} / \mathrm{m}^{2}(A), 200 \mathrm{~g} / \mathrm{m}^{2}$ (B), $400 \mathrm{~g} / \mathrm{m}^{2}$ (C), and $800 \mathrm{~g} / \mathrm{m}^{2}$ (D). The results of these simulations indicate that huntergatherers decrease their hunted foods (solid line) to a greater extent (abundance in the stable limit cycle/the maximum initial abundance) than their gathered foods (dashed line) as the harvestable primary productivity increases.

allows larger human populations to be maintained when hunted foods are rare; this results in the demise of the hunted foods.

The results from the model presented here are counter to the predictions from overexploitation models, where prey extinction is more likely at low primary productivities, not high productivities as predicted here. Also, the key to the demise of hunted foods is not their productivity or abundance, but the productivity of gathered foods. These results depend upon the foraging model's prediction that hunted foods are generally more preferred than gathered foods (Belovsky 1987) and gathered foods increase in the diet as hunted foods are reduced in abundance. If the gathered foods are abundant enough to maintain the humans at high densities, the exploitation of hunted foods will remain high even if the hunted foods are reduced.

Analysis of arguments that hunter-gatherers culturally prevent overexploitation or manage their food resources for maximum sustained yield is 
more difficult to examine (Hames 1987). Various cultural restrictions to food exploitation are known (Webster 1981; Webster and Webster 1984), but their significance for human and food population dynamics is not known. In a recent study, Vickers (1988) argues that the movement of some South American Indian villages cannot be explained by the depletion of prey populations, since game populations are not depleted. These people, however, are not hunter-gatherers, but agriculturalists who also hunt. To test the idea that hunter-gatherers culturally prevent overexploitation of their foods will require far more detailed data on the dynamics of food utilization (Hames 1987). These data can then be compared with the predictions of a model (like that presented here); a failure to find agreement might indicate cultural restrictions to exploitation.

However, there already is some indication that hunter-gatherers do not prevent overexploitation of their foods by cultural means. First, there are anecdotal accounts of hunter-gatherers reducing the abundances of their foods (Webster 1981; Webster and Webster 1984). Second, the observed densities of hunter-gatherers, as presented above, are comparable to those predicted by the model (Fig. 8A). If these people were reducing their exploitation or attempting to manage their food for maximum sustained yield, the observed hunter-gatherer average densities might be higher and their population variation would be much lower than predicted by the model. Therefore, the very limited data on hunter-gatherer demography are not consistent with culturally reduced food exploitation.

\section{Hunter-Gatherer Dietary Changes during Population Growth}

Because hunter-gatherers have changing densities and food abundances over time, we should expect their diets also to change over time. These dietary changes never end since the hunter-gatherer populations are predicted to have a stable limit cycle. This means that the diet will also have a stable cycle as long as one food is not overexploited to extinction.

More important are the patterns in diet change that occur during the growth of the human population from an initial low density to its stable limit cycle. The predicted average diets at different stages of population growth in environments with different harvestable primary productivities can be compared. Three stages of population growth can be denoted: the initial colonizing population with few dependents (initial: until a stable age distribution is achieved); the period of population establishment (growth: from the attainment of a stable age distribution until the stable limit cycle is achieved); and the stable limit cycle (established).

The average diets at each stage of population growth in environments of different harvestable primary productivities are presented in Fig. 10. At all harvestable primary productivities except $100 \mathrm{~g} / \mathrm{m}^{2}$, the initial stages of 


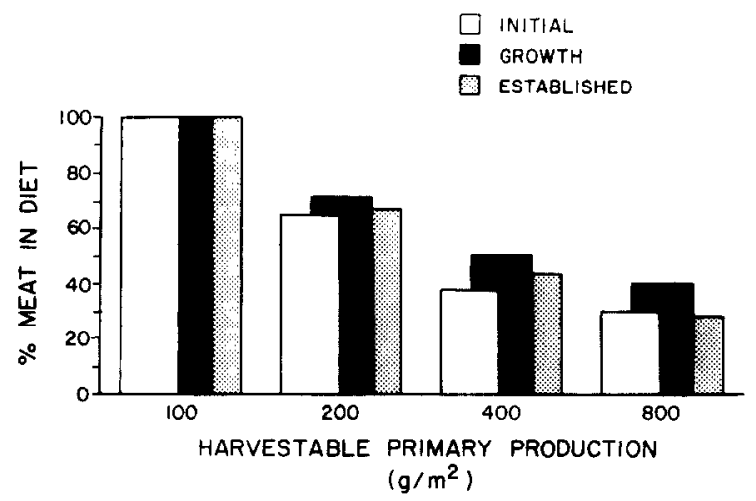

FIG. 10. Dietary changes in environments with different harvestable primary productivities and at different stages of the population growth trajectory are presented. Three stages of the population growth trajectory are denoted: initial (prior to establishment of a stable age distribution), growth (stable age distribution prior to achieving a stable limit cycle), and established (a stable limit cycle). The model predicts that the diets at a given harvestable primary productivity are lower or equal in hunted foods during the initial and established phases than during the growth phase.

population growth are marked by a diet that is lower in hunted foods than during the next period. The diet in the initial phase is lower in hunted foods because the diet model constraints are based on a low ratio of dependents to adults; while a constant higher ratio occurs in the growth phase. Once the population becomes established within its stable limit cycle, the proportion of hunted foods decreases in the diet, unless the hunted foods have previously been overexploited to extinction. The diet changes for established populations arise with modifications in the foraging model's constraints due to:

(1) a lower dependent to adult ratio as the population stops its continual growth and enters a stable limit cycle, and

(2) the reduction in the abundance of hunted foods to a lower average level within the stable limit cycle.

\section{An Archaeological Example of the Model's Utility}

The model provides a set of predictions about changes in huntergatherer population densities, food abundances, and diet composition in different environments. These critical aspects affect how people have changed their lifeways over time. As an example, the model was used to examine the colonization of the New World by Paleo-Indians. There are several reasons for choosing this example. It is a topic widely discussed due to the claim that this colonization by humans may have caused the 
extinction of North American Pleistocene megafauna (Fiedel 1987; Butzer 1971). Also, the "semi-controlled" nature of observations on cultural development in a previously uninhabited land provides an ideal data set to compare with the model's predictions, since complications of past human influences on the environment are eliminated. Finally, it is an example for which other models of hunter-gatherer population dynamics, in particular models of overexploitation of hunted foods, have been developed (Martin 1973, 1982, 1984; Mosimann and Martin 1975; Whittington and Dyke 1984; Budyko 1967, 1974).

The model presented here, or any model, cannot be used to prove or disprove a particular view. The model can be used as a hypothesis against which observations can be compared to see whether or not the hypothesis (model) can be falsified. Therefore, the model may raise more questions than provide answers, which can be as useful.

The New World environment must be described at the time of first human occupation. Although there still is debate over when humans first colonized the New World, there is a growing concensus based upon a variety of lines of evidence that the first colonizations occurred between 15 and 12 thousand years ago (Fiedel 1987; Lewin 1987). At this time, the approximate habitable area of North and South America would have been $9 \times 10^{6}$ and $17 \times 10^{6} \mathrm{~km}^{2}$, respectively, due to the effects of glaciation (Fiedel 1987; Martin 1973; Mosimann and Martin 1975).

The New World can be dissected into vegetation communities as reconstructed by paleobotanists and paleozoologists (e.g., Jennings 1983; McDonald 1984) and a primary productivity level can be assigned to each vegetation type (e.g., Whittaker 1970). It is important to remember that the primary productivity values must reflect the primary productivity harvestable by humans or their prey animals (Belovsky 1987). This value is much smaller than the total primary productivity in forested regions and these modifications in total primary productivity are accounted for using figures provided in Belovsky (1987).

The hunter-gatherer population model can be solved for each vegetation type. However, rather than tracing the growth of the human population from vegetation type to vegetation type across the two continents, an average primary productivity was used. An average harvestable primary productivity of approximately $200 \mathrm{~g} / \mathrm{m}^{2}$ in the New World was estimated.

Before examining the spread of hunter-gatherers across the two continents, a simple set of rules must be established on how humans disperse into uninhabited areas. This dispersal can be defined using ideas from animal ecology. "Patch selection" theory (Charnov 1976; Stephens and Krebs 1986) argues that an animal should leave a patch of habitat when its 
fitness (survival and reproduction) falls below what could be attained on average in the environment. This theory is related to another ecological theory, "free distribution," in which the "patch selection" criteria would lead to individuals in a population being distributed in different patches at densities that would provide equal fitness (Fretwell and Lucas 1970).

Using these ecological theories and the predictions for hunter-gatherer populations with an average productivity of $200 \mathrm{~g} / \mathrm{m}^{2}$ (Fig. 6), human dispersal can be examined. Once a stable age distribution is attained, the human population will grow at a constant high rate until the population density peaks and enters the stable limit cycle phase (Fig. 6). Once the population enters the stable limit cycle, the growth rate declines precipitously (Fig. 6). Therefore, a population starting from an initial small number of colonists (e.g., a male-female pair) will grow to the density where the population growth begins to decline (approximately 12.5 individuals $/ 100 \mathrm{~km}^{2}$ ). At this point additional individuals will attain higher fitness by dispersing into uninhabited areas, if available, rather than staying within the original population.

The outcome of the dispersal process is maintenance of the original population at the maximum density where the growth rate also is maximum (approximately 12.5 individuals $/ 100 \mathrm{~km}^{2}$ ), and establishment of new populations by the surplus individuals produced. The new populations in turn will grow until they reach a density of 12.5 individuals $/ 100 \mathrm{~km}^{2}$ and then their surplus individuals will begin to disperse. The time required for a population to reach the dispersal phase, where the only influx of dispersing individuals to each population is the original colonizing pair, is approximately 120 years. When all areas are inhabited by human populations at a density of $12.5 / 100 \mathrm{~km}^{2}$, then the populations will continue to grow and enter the stable limit cycle phase.

Predictions about the colonization of the New World can be made and compared with the predictions of other models developed to examine the overexploitation of prey animals (Fig. 11). As in the overexploitation models, the Paleo-Indians are assumed to have arrived in the vicinity of Edmonton, Canada at approximately 11,500 B.P. The model presented here and the overexploitation models provide comparable time frames for colonization, a wave-like movement of colonizers (a colonizing front), and comparable densities when the continents are fully populated (Fig. 11). Therefore, there is no difference in terms of the general picture of colonization by Paleo-Indians of the New World provided by the model presented here or models for overexploitation of prey (Haynes 1970, 1982; Martin 1973, 1982; Mosimann and Martin 1975).

Whether or not a widespread overexploitation and extinction of the large prey animals occurs with this colonization is a main difference generated by the model presented here and those developed to examine 


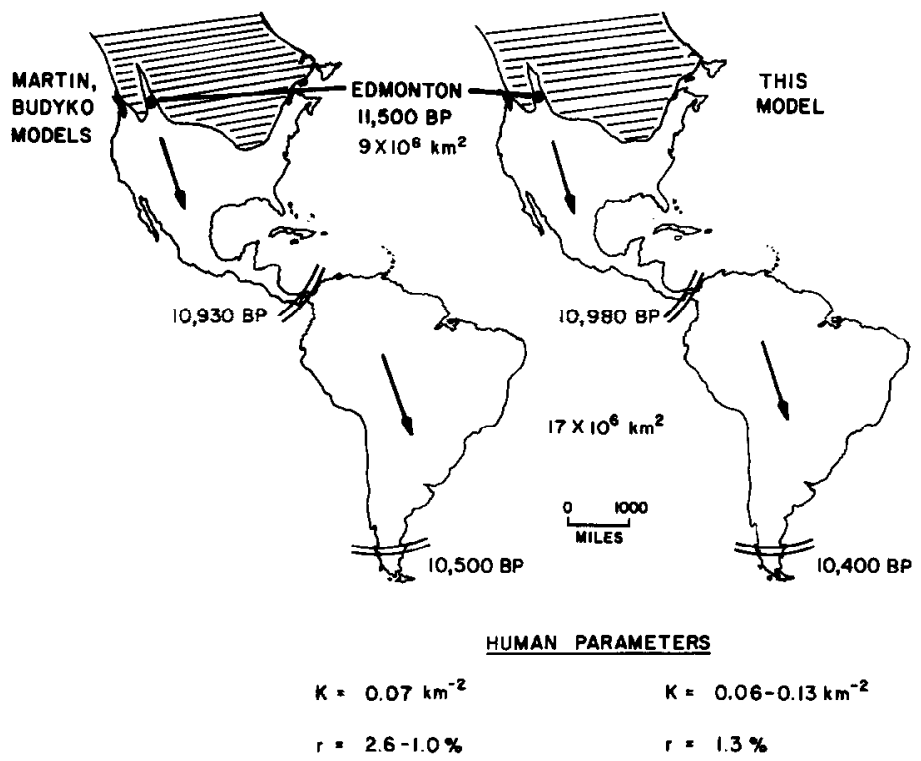

FIG. 11. Predictions for the chronology of colonization in the New World by PaleoIndians are compared for the model presented here and the models developed to examine megafaunal overkill. $(\mathrm{K})$ refers to human carrying capacity and $(r)$ is the maximum population growth rate.

overexploitation. The model presented here does not predict a general demise of large prey animals (Fig. 10). However, it is possible that the extinction of prey by overexploitation might occur in some of the environments composing the hypothetical $200 \mathrm{~g} / \mathrm{m}^{2}$ average productivity.

As presented above, prey are predicted to go extinct by overexploitation in the more productive environments $\left(>500 \mathrm{~g} / \mathrm{m}^{2}\right)$; these areas would not include forested areas but could include the most productive savannalike habitats of the Mexican highlands and tallgrass prairie (Whittaker 1970; Leith 1975). Another habitat where prey extinction might occur by overexploitation would be the very productive areas in river floodplains. Nonetheless, these habitats where megafaunal overexploitation and extinction might occur are not widespread enough to account for the range of observed extinctions at the end of the Pleistocene.

Furthermore, even the highest estimates of plant productivity for areas with the highest observed megafaunal extinctions are not large enough for the model presented here to predict that hunter-gatherers would overexploit their prey. These areas include the tundra bordering the glaciated areas and the Beringian grasslands (Redmann 1982; Schweger 1982; Bliss and Richards 1982; Hibbert 1982). Therefore, the observed megafaunal extinctions cannot be accounted for by the model presented here, sug- 
gesting that factors other than overexploitation (e.g., climatic changes) might be the cause (Wesler 1981; Guthrie 1982, 1984; Grayson 1984).

The model's predictions for megafaunal extinction might be criticized since the large prey animals (hunted foods) are treated as a composite group. This means that a single or a few species (e.g., mammoths and mastodons) might be overexploited by hunter-gatherers and this distinction might not be identified by the model. The models of overexploitation (see references above) also fail to make this distinction. This, however, is a moot point since the large-scale megafaunal extinction at the end of the Pleistocene in the New World was well beyond one or a few species going extinct at each location (Martin 1984).

One aspect of megafaunal extinction cannot be addressed by the model presented here. If hunter-gatherers overexploit the largest prey (e.g., mammoths, mastodons, etc.) and the prey's demise eliminates their effect on the habitat (disturbance) which in turn reduces food production for other megafauna, then additional extinctions might occur (Owen-Smith 1987). Although I do not place much stock in this hypothesis since the largest megafauna do not seem to have been very abundant in the New World (Guthrie 1968, 1982, 1984) and this hypothesis is not consistent with some observations on modern megafaunal communities (Belovsky in preparation), this is a possibility that cannot be discarded.

While the model of hunter-gatherer populations presented here is not consistent with claims of megafaunal overexploitation, there are other provocative predictions that the model provides. The first deals with the archaeological evidence for diet changes and the onset of the Archaic in the New World, and the second deals with the adoption of new technologies for food acquisition.

Dietary changes for Paleo-Indians as indicated in the archaeological record of the New World pose two problems. Some Paleo-Indian sites of comparable age in a locale indicate a diet based on a more equitable harvesting of hunted and gathered foods and a tool kit reflecting this more diverse diet, while other sites in the same locale and of comparable age indicate a diet dominated by hunted foods and a tool kit for big-game hunting (Fiedel 1987; Butzer 1971; Lynch 1978, 1983; Jennings 1983). Two explanations which have been suggested are: (1) the existence of sympatric but distinct cultures, one specializing in big game hunting and the other exploiting a more diverse diet, or (2) the possibility of a single culture with seasonal differences in food use. The model presented here suggests another intriguing possibility: could the sites reflecting a more diversified diet (lower in hunted foods) represent different population growth phases, either the initial or the established phase (Fig. 10)? This would be difficult to ascertain from the archaeological record unless a single stratified site 
containing both types of tool kits could be found, since the resolution of radiocarbon dating is not accurate enough to distinguish the time frame of the transition from the initial to the growth phase of the population trajectory (less than 25 years), or for the transition from the growth to the established phase (approximately 100 years).

Diet changes also are used, in part, to delineate the end of the PaleoIndian period and the onset of the Archaic. The model presented here provides the tantalizing suggestion that initiation of the Archaic might reflect the transition from a population's growth phase to its established phase (Fig. 10), when it enters a stable limit cycle and the diet includes a lower proportion of hunted foods. Therefore, this would imply that PaleoIndians sites with a lower intake of hunted foods (see above) are possibly sites from the initial population phase, when people were first colonizing a locale, and that early Archaic sites are the onset of the established population phase.

The population model presented here provides an estimate that the populations in the New World would have reached the established phase (no more areas to colonize) in some parts of the New World by 9500 B.P. With the retreat of the glaciers opening new area to colonization, an established phase may not have been achieved until 7000 B.P. in other parts of the New World. Furthermore, in areas which had a low harvestable primary productivity at the time of colonization and after Holocene vegetation changes, a diet high in hunted foods would have been perpetuated, showing little dietary change (Fig. 10). Therefore, the emergence of the Archaic in different parts of the New World at different times is consistent with this scenario (Fiedel 1987). An earlier emergence is predicted and found in environments of higher harvestable primary productivity (e.g., some Mexican and South American savanna-like habitats) and a late appearance of the Archaic is predicted and found in the plains areas of North America with lower harvestable primary productivities (Flannery 1986; Frison 1974, 1978; Lynch 1978, 1983; Butzer 1971; Fiedel 1987).

Questions dealing with dietary change indicate the need to investigate plant use (gathered foods) by Paleo-Indians more thoroughly, since the model suggests that Paleo-Indians might have relied extensively on plant foods, even when meat intake was great (Fig. 10). The abundance of plant foods and their use also influence the severity of exploitation of the prey. Therefore, this investigation of changing lifeways with demography and food resources should be viewed as a suggestion requiring much greater refinement in the model and data collection.

The adoption of new technologies poses another important archaeological question that can be addressed using the model. A new technology 
reflects new tools or methods for food procurement that decrease the time it takes to harvest a unit of food (decreases the model's cropping rates). The result is that the forager will be able to harvest more food in the same amount of time even though the amount of harvestable food in the environment does not change. For the purposes of this paper, new methods of food procurement that change the amount of harvestable food in the environment (e.g., agriculture) are not examined; these will be addressed in a future paper.

To address the role of technology in the model, the portion of the cropping rates due to food harvesting (not including search or preparation) was increased by $5 \%$ (food acquired per unit time). The search for food was not included in the change since this is primarily a function of the food's abundance in the environment; preparation was not included since this was considered to be a constant characteristic for the food type (butchering, cooking, etc.). Averaged over environments of different productivities, a 5\% increase in harvesting ability leads to an increase in energy intake of 7-8\%, a decrease in meat consumption of $12-13 \%$ and an increase in hunter-gatherer density and growth rates of $17-18 \%$. Therefore, a small change in technology can have a very large effect on population density and growth rate.

Population growth rates and densities reflect the fitness of individuals in small populations, like hunter-gatherer groups. Therefore, we might expect advances in technology to be rapidly adopted, since a small change in cropping rate has a large impact on energy intake and population dynamics. As an example of how important this cultural evolution might be for humans, changes in hominid densities can be examined. Estimates of densities of Homo habilis in East Africa 2.5 million years ago average 0.01 individuals $/ \mathrm{km}^{2}$ (Tanner 1981) and modern hunter-gatherers in these areas have an average density of 0.1 individuals $/ \mathrm{km}^{2}$ (Hassan 1981). The $900 \%$ greater density observed today, ignoring environmental changes, could have arisen from a mere $25-26 \%$ increase in food gathering technology over the last 2.5 million years!

The observed rapid changes in Paleo-Indian lithic technologies could easily be a reflection of the cultural evolution of people to changing demography, its impact upon food resources, and environmental changes. Therefore, we should not be surprised by the rapid appearance and disappearance of technologies in the archaeological record. These changes could easily have occurred by people adopting another group's technology when it was found to be more efficient or by the competitive exclusion of hunter-gatherer groups with different (less efficient) technologies. The importance of technological innovations for hunter-gatherer demography, however, emphasizes the need to provide experimental data on the 
use of ancient technologies (e.g., Frison 1974, 1978, 1982; Oswalt 1979; Bleed 1986; Browne 1940; Hames 1979; Hill 1948; Kellar 1955; Lahren and Bonnichsen 1974; Peets 1960; Stanford et al. 1981; Huckell 1979; Kleindienst and Keller 1975). This will permit the cropping rate values employed in models like the one presented here to be made more realistic, so model predictions can have greater utility to archaeologists.

\section{CONCLUSION}

The model presented here hopefully illustrates the utility of combining models of hunter-gatherer foraging behavior with their demography and the demography of their food resources. The model's predictions are consistent with the limited available data on present day huntergatherers. Furthermore, the model provides predictions that are consistent with archaeological evidence on the colonization of the New World by Paleo-Indians. Like any other hypothesis, however, the model presented here raises many new questions and emphasizes the need for new data to be collected in ways that may not have been previously considered.

Most importantly, the model indicates that, at least for huntergatherers, their demography and foraging technologies may be environmentally determined (Buikstra and Mielke 1985). These people must be viewed as adapted to their environments and subject to the same environmental restrictions that apply to other animals. Past claims that these people culturally limit their population sizes or are not subject to shortfalls in food that appear in an environment with limited food resources cannot be reconciled with the model presented here or the consistent empirical data (Hassan 1981; Glassow 1978). The key to these past misconceptions is an outdated view of carrying capacity, where carrying capacity was viewed as a static quantity that did not change with or change hunter-gatherer demography.

Refinement of the model presented here or Winterhalder et al.'s (1988) model will depend upon a better understanding of foraging models for hunter-gatherers and their nutritional needs. The model presented here and Winterhalder et al.'s are based upon different foraging models (see Belovsky 1987). While both population models provide similar general results, the detailed quantitative predictions will be very different. Therefore, as these models are used to address more specific questions about hunter-gatherers, distinctions as to which foraging model is more appropriate will be necessary. In this paper a quantitative argument is presented for the utility of the foraging model construct developed in Belovsky (1987). 


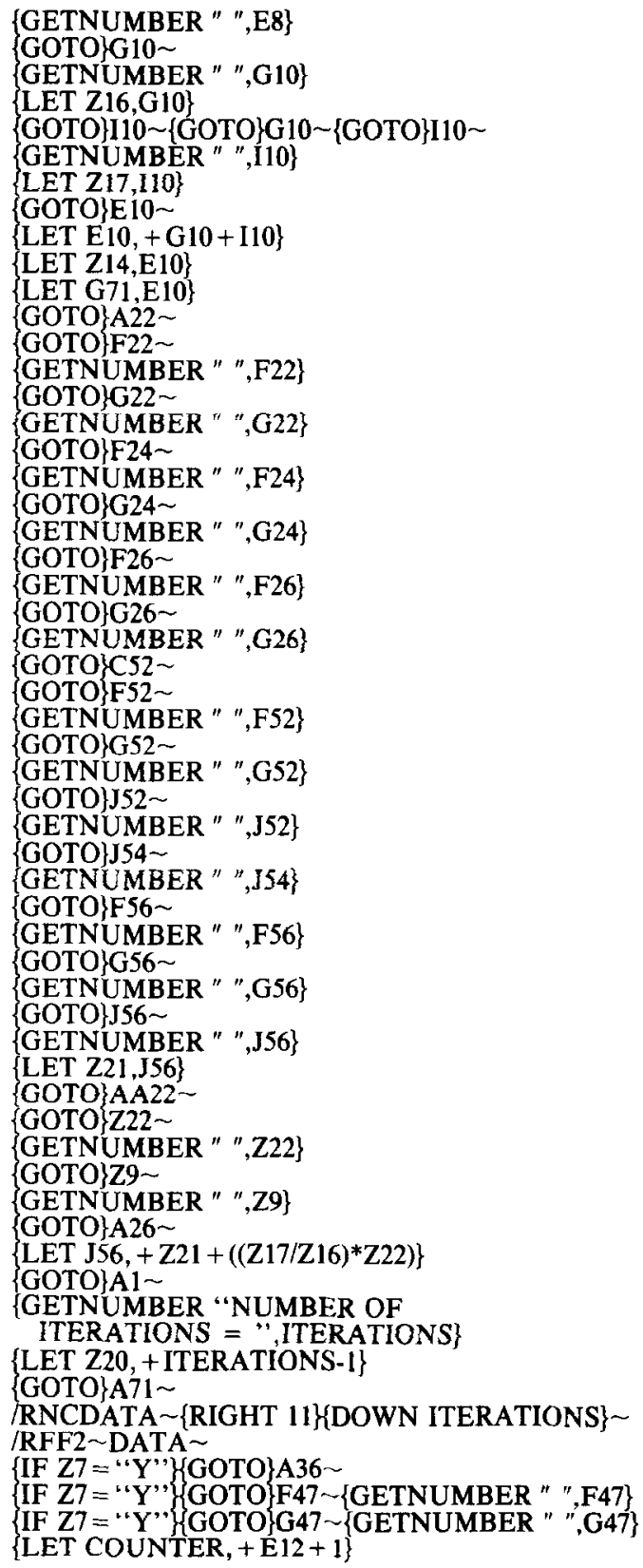

〈FIRST COMPUTE $\quad$ \{LET $224,+\mathrm{Z17/Z16}\}$

$\{$ LET J56, + Z21 + Z24*Z22

LET J52, + 700 + (Z24*332.5)\}

$\{$ LET F $54,+.28+(25 /(((\mathrm{G} 22 * 50)-(\mathrm{G} 22-\mathrm{G} 26)) *(\mathrm{~F} 26 / \mathrm{F} 22)))\}$ 


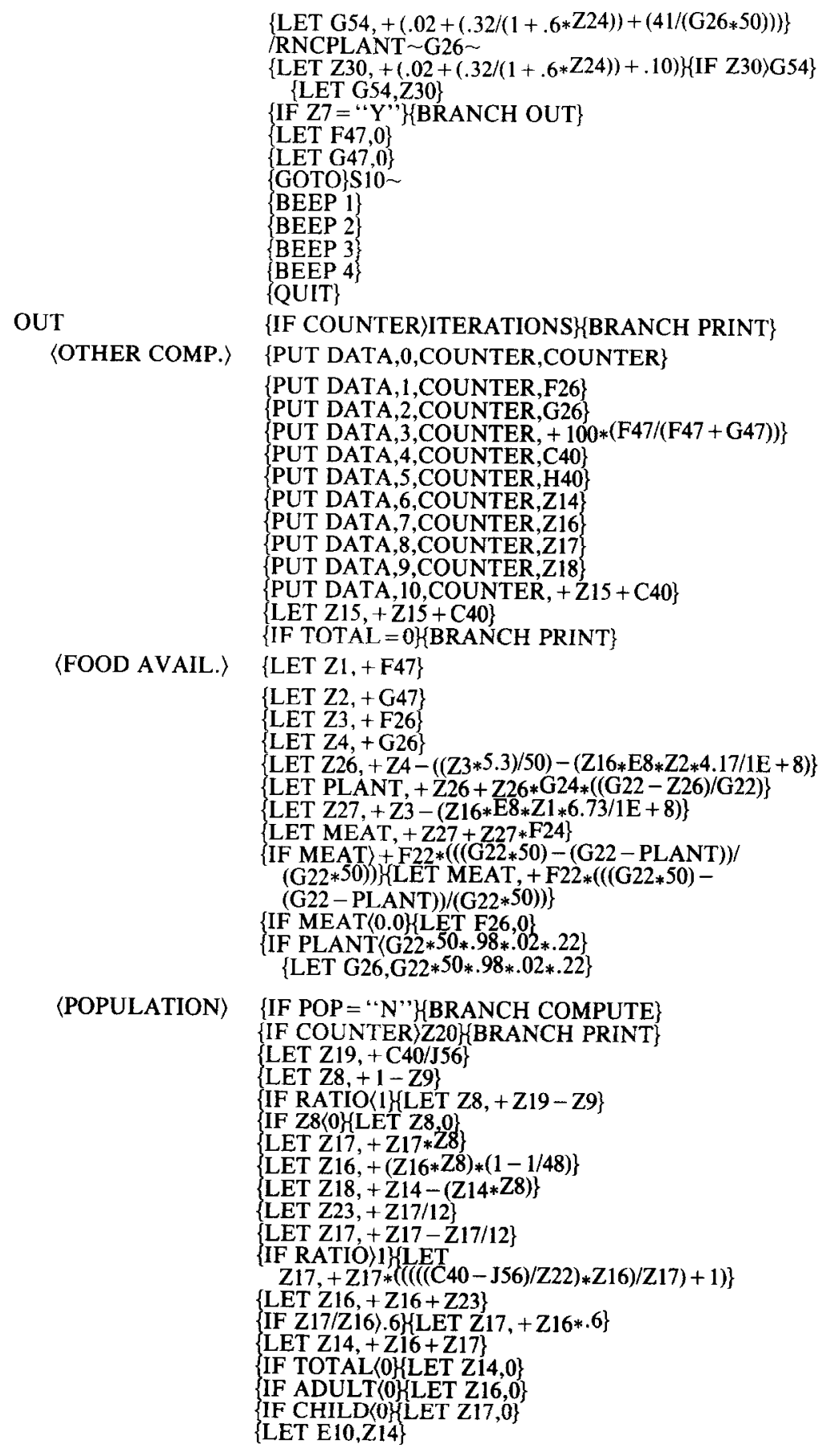




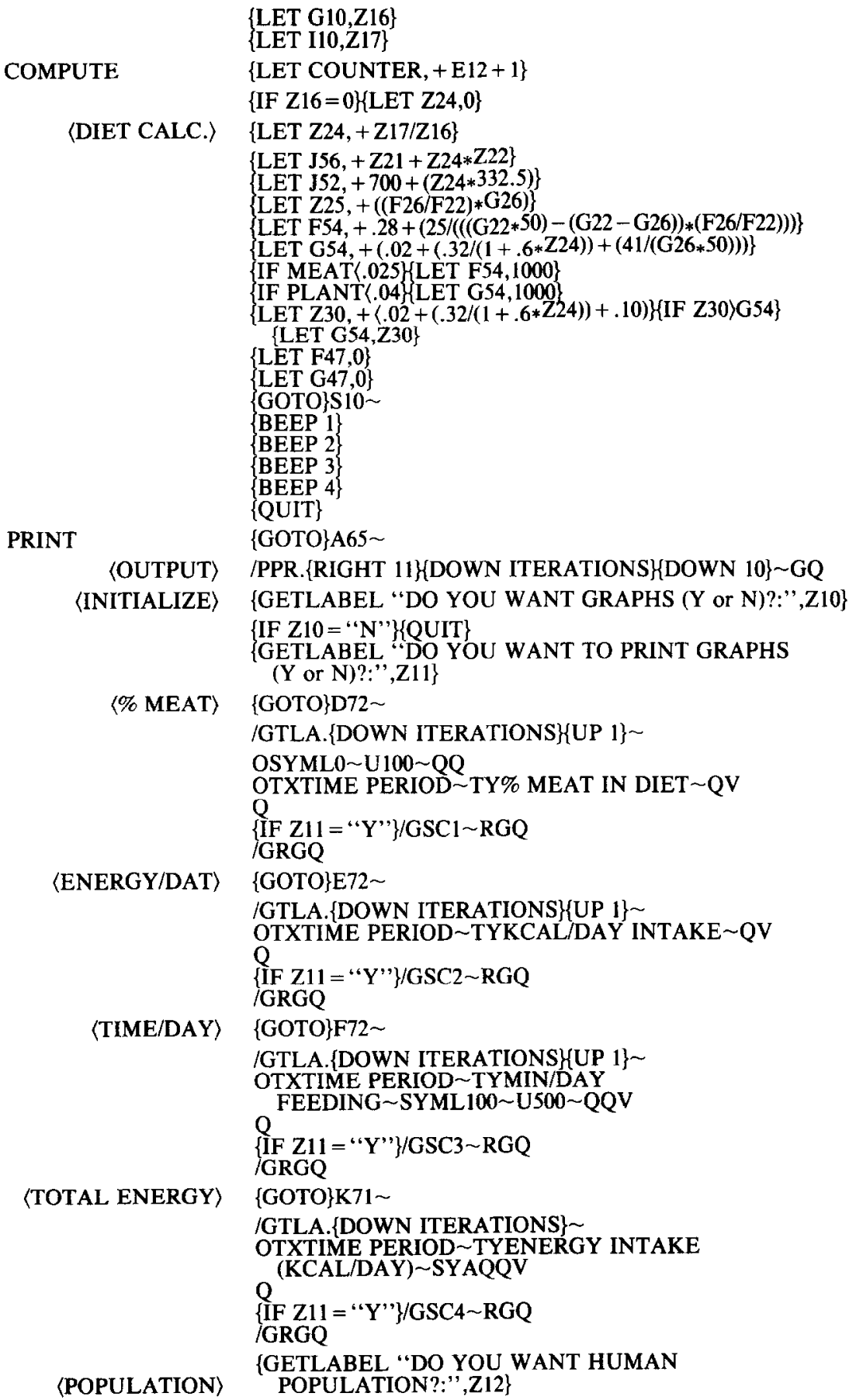




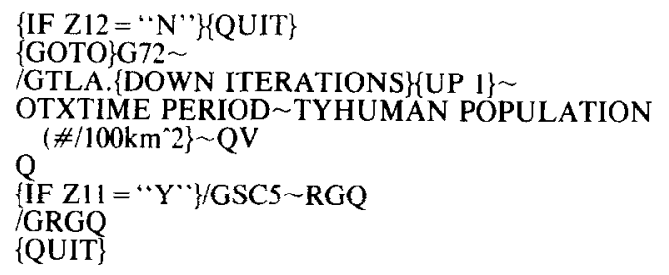

\section{APPENDIX \|}

\section{Stability Analysis of Overexploitation Models}

A set of simple differential equations can be used to analyze the stability of models which various authors have employed to determine whether or not Paleolithic peoples might have overexploited game animals and caused their extinction (Martin 1973, 1982, 1984; Mosimann and Martin 1975; Whittington and Dyke 1984; Budyko 1967, 1974). Stability analysis examines whether or not population growth trajectories (changes over time) will generally approach an equilibrium (constant outcome) regardless of the initial conditions (population densities at the start) and whether or not they will return if disturbed from an equilibrium. Differential equations (continuous changes over time) were employed even though many of the original formulations (Martin 1973, 1982, 1984; Mosimann and Martin 1975; Whittington and Dyke 1984) employed difference equations (discrete changes over time) because differential equations are easier to use in a stability analysis and are more stable; i.e., if they are unstable so are the difference equations (May 1973).

The set of differential equations employed is:

$$
F_{1}(P, H)=d P / d t=r(P-g H) \quad \text { for } P<K ;
$$

otherwise

$$
d P / d t=0 \quad \text { and } \quad P=K,
$$

and

$$
F_{2}(H)=d H / d t=b H(L-H) / L,
$$

where $P=$ the density of game animals; $K=$ the carrying capacity of the game animals, their maximum density; $H=$ the density of humans; $r=$ the intrinsic growth rate of the prey animals; $g=$ the number of game animals killed by each human; $b=$ the intrinsic growth rate of the humans; and $L=$ the carrying capacity of the humans, their maximum density. 
Several characteristics of these proposed population models should be noted. First, the number of game animals killed per human $(g)$ does not change with game or human population densities. There is no feedback between prey abundance and human hunting success. This has been argued for on the grounds that humans are so efficient that they can find and kill all large prey animals in the environment (Budyko 1967, 1974; Martin 1973; Mosimann and Martin 1975). Mosimann and Martin (1975) did allow $g$ to be dependent upon prey abundance, but this had no effect on the model's general predictions. Second, the human carrying capacity, $L$, is not a function of prey abundance, but a constant. Therefore, prey abundance cannot provide feedback to human population density.

$F_{2}(H)$ is the classic logistic equation from ecology. This equation was not used by Budyko $(1967,1974)$ who employed the exponential growth equation. Since Budyko's equation does not account for any limit to human population growth, the people increase in number indefinitely until all the prey animals are killed (extinction). Therefore, Budyko's model does not provide the possibility for a stable coexistence between humans and their prey animals; megafaunal extinction is a foregone conclusion.

The use of the logistic growth equation for humans with a maximum population density, $L$, provides a potential equilibrium between humans and their prey animals, which has been recognized by the authors of these models. This equilibrium is shown in Fig. A1 and has the following characteristics:

$$
P^{*}=g H, \quad \text { if and only if } L \leqslant r K / g(1+r),
$$

and

$$
H^{*}=L,
$$

where the ${ }^{*}$ denotes the equilibrium solution. If $L>r K / g(1+r)$, then the

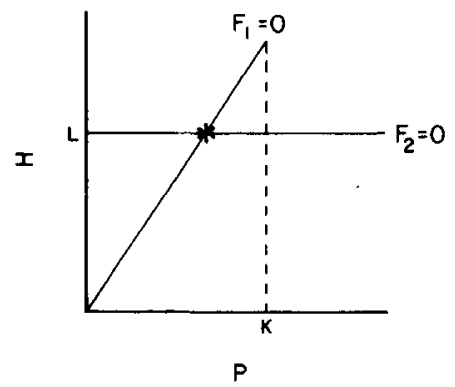

FIg. Al. Plots of the population isoclines $\left(F_{1}=0\right.$ and $\left.F_{2}=0\right)$ as functions of prey $(\mathrm{P})$ and human $(\mathrm{H})$ densities. The intersection of the isoclines $(*)$ reflects the equilibrium densities. The dashed line represents the disjunct prey isocline at its carrying capacity. 
prey animals are driven to extinction. Even though an equilibrum is possible, it is not necessarily stable, meaning that these constant densities cannot be attained unless the populations are placed at these densities as an initial condition, nor will they return to the equilibrium if perturbed.

To examine the stability of this potential equilibrium, the eigenvalues must be examined for this system of interacting populations. Eigenvalues describe a population's growth trajectory in the vicinity of an equilibrium to determine whether or not the trajectory approaches the equilibrium or moves away from it. Also, the eigenvalues explain whether the trajectory moves in a unidirectional or in an oscillatory fashion. For a system to be stable all eigenvalues, one for each population equation, must have a negative real part; if they do not, the system is not stable (May 1973). If the eigenvalues also have an imaginary part, then the trajectory will be oscillatory (May 1973).

To compute the eigenvalues we need to know the partial derivatives of $F_{1}$ and $F_{2}$ with respect to $H$ and $P$ in the vicinity of the equilibrium. These partial derivatives are found by taking the derivative of $F_{1}$ and $F_{2}$ with respect to $H$ and $P$ and then substituting the equilibrium values, $H^{*}$ and $P^{*}$, for any remaining $H$ and $P$ values. These partial derivatives are presented in the matrix

$$
A=\left|\begin{array}{ll}
r & -r g \\
0 & -b
\end{array}\right|
$$

and the eigenvalues are solved given the relationship

$$
\operatorname{det}|A-\lambda I|=\mathbf{0}
$$

where $I$ is the identity matrix and $\lambda$ is the column matrix of eigenvalues.

For the population models constructed to examine the potential for overexploitation of prey animals, the eigenvalues are $\lambda_{1}=r$ and $\lambda_{2}=$ $-b$. Because one of the eigenvalues is not negative, this system of population equations is unstable. This means that even though an equilibrium between humans and their prey animals is possible in this set of equations it is unstable. Therefore, humans will always hunt their prey to extinction in these models; there is no other alternative.

\section{ACKNOWLEDGMENTS}

I thank R. Whallon, J. B. Slade, and an unidentified reviewer for detailed comments on the manuscript. I also acknowledge conversations with R. Whallon, J. Speth, B. Winterhalder, and $\mathrm{K}$. Flannery on aspects of this paper. 


\section{REFERENCES CITED}

Abrams, Peter

1984 Variability in resource consumption rates and the coexistence of competing species. Theoretical Population Biology 25:106-124.

Angel, J. L.

1975 Paleoecology, paleodemography and health. In Population, ecology, and social evolution, edited by Steven Polgar, pp. 167-190. Mouton, The Hague.

Belovsky, Gary E.

1978 Diet optimization in a generalist herbivore: The moose. Theoretical Population Biology 14:105-134.

1984a Herbivore optimal foraging: A comparative test of three models. American Naturalist 124:97-115.

1984b Summer diet optimization by beaver. American Midland Naturalist 111:209 222.

1986 Generalist herbivore foraging and its role in competitive interactions. American Zoologist 26:51-69.

1987 Hunter-gatherer foraging: A linear programming approach. Journal of Anthropological Archaeology 6:29-76.

Belovsky, Gary E., Mark E. Ritchie, and Jeffrey Moorehead

1989 Foraging in complex environments: When prey availability varies over time and spacc. Theoretical Population Biology.

Birdsell, Joseph B.

1957 Some population problems involving Pleistocene man. Population studies: Animal ecology and demography. Cold Springs Harbor Symposium on Quantitative Biology 22:47-69.

1968 Some predictions for the Pleistocene based on equilibrium systems among recent hunter-gatherers. In Man the hunter, edited by Richard Lee and Irvin DeVore, pp. 229-240. Aldine, Chicago.

Bleed, $\mathbf{P}$.

1986 The optimal design of hunting weapons: Maintainability or reliability. American Antiquity 5:737-747.

Bliss, L. C., and James H. Richards

1982 Present-day arctic vegetation and ecosystems as a predictive tool for the arcticsteppe mammoth biome. In Paleoecology of Beringia, edited by David M. Hopkins, John V. Matthews, Jr., Charles E. Schweger, and Steven B. Young, pp, 241-257. Academic Press, New York.

Blurton Jones, Nicholas G., and R. M. Sibley

1978 Testing adaptiveness of culturally determined behavior: Do Bushmen women maximize their reproductive success by spacing births widely and foraging seldom? In Human behaviour and adaptation, edited by Nicholas G. Blurton Jones and V. Reynolds, pp. 135-157. Society for the Study of Human Biology Symposium No. 18. Taylor \& Francis, London.

Browne, Jim

1940 Projectile points. American Antiquity 5:209-213.

Budyko, M. I.

1967 On the causes of the extinction of some animals at the end of the Pleistocene. Soviet Geography: Review and Translation 8:783-793.

1974 Climate and life. Academic Press, New York. 
Buikstra, Jane E., and James H. Mielke

1985 Demography, diet, and health. In The analysis of prehistoric diets, edited by Robert I. Gilbert, Jr., and James H. Mielke, pp. 359-422. Academic Press, New York.

Butzer, K. W.

1971 Environment and archeology: an ecological approach to prehistory. AldineAtherton, Chicago.

Caughley, Graeme, and John H. Lawton

1981 Plant-herbivore systems. In Theoretical ecology: principles and applications, edited by Robert M. May, pp. 132-166. Sinauer Associates, Sunderland, MA.

Charnov, Eric L.

1976 Optimal foraging, the marginal value theorem. Theoretical Population Biology 9:129-136.

Comins, H. N., and M. P. Hassell

1979 The dynamics of optimally foraging predators and parasitoids. Journal of Animal Ecology 48:335-351.

Deevey, Edward S., Jr.

1960 The human population. Scientific American 203:194-204.

Emlen, J. Merritt

1966 The role of time and energy in food preference. The American Naturalist 100:611-617.

Farlow, James O.

1976 A consideration of the trophic dynamics of a late Cretaceous large-dinosaur community (Oldman Formation), Ecology 57:841-857.

Fiedel, Stuart J.

1987 Prehistory of the Americans. Cambridge Univ. Press, Cambridge.

Flannery, Kent V.

1986 The research problem. In Guila Naquitz: Archaic foraging and early agriculture in Oaxaca, Mexico, edited by Kent V. Flannery, pp. 3-18. Academic Press, Orlando, FL.

Fretwell, Stephen D., and H. L. Lucas, Jr.

1970 On territorial behavior and other factors influencing habitat distribution in birds. I. Theoretical development. Acta Biotheoretica XIX(1):16-36.

Frisancho, A. Roberto

1981 Human adaptation: A functional interpretation. Univ. of Michigan Press, Ann Arbor.

Frison, George C.

1974 Archaeology of the Casper site. In The Casper site: A Hellgap bison kill on the high plains, edited by George C. Frison, pp. 1-112. Academic Press, New York.

1978 Prehistoric hunters of the high plains. Academic Press, New York.

1982 Bison procurement. In The Agate Basin site: A record of the Paleoindian occupation of the northwestern high plains, edited by George C. Frison and D. J. Standord, pp. 263-269. Academic Press, New York.

Glassow, M. A.

1978 The concept of carrying capacity in the study of culture process. Advances in Archaeological Method and Theory 1:31-48.

Grayson, Donald K.

1984 Nineteenth-century explanations of Pleistocene extinctions: A review and analysis. In Quaternary extinctions: A prehistoric revolution, edited by Paul S. Martin and Richard C. Klein, pp. 5-39. Univ. of Arizona Press, Tucson. 
Guthrie, R. Dale

1968 Paleoecology of the large-mammal community in interior Alaska during the Late Pleistocene. American Midland Naturalist 79:346-363.

1982 Mammals of the mammoth steppe as paleoenvironmental indicators. In Paleoecology of Beringia, edited by David M. Hopkins, John V. Matthews, Jr., Charles E. Schweger, and Steven B. Young, pp. 307-326. Academic Press, New York.

1984 Mosaics, allelochemics and nutrients: An ecological theory of late Pleistocene megafaunal extinctions. In Quaternary extinctions: A prehistoric revolution, edited by Paul S. Martin and Richard C. Klein, pp. 259-298. Univ. of Arizona Press, Tucson.

Hames, R. B.

1979 A comparison of the efficiencies of the shotgun and the bow in neotropical forest hunting. Human Ecology 7:219-252.

1987 Game conservation or efficient hunting? In The question of the commons: The culture and ecology of communal resources, edited by Bonnie J. McCay and James M. Acheson, pp. 92-107. Univ. of Arizona Press, Tucson.

Harper, John L.

1977 Population biology of plants. Academic Press, London.

Hassan, Ferki. A.

1975 Determination of the size, density, and growth rate of hunting-gathering populations. In Population, ecology and social evolution, edited by Steven Polgar, pp. 27-52. Mouton, The Hague.

1981 Demographic archaeology. Academic Press, New York.

Hassell, M. P., and Robert M. May

1973 Stability in insect host-parasite models. Journal of Animal Ecology 42:693-726.

Hawkes, K., K. Hill, and J. F. O'Connell

1982 Why hunters gather: Optimal foraging and Ache of eastern Paraguay. American Ethnologist 9:379-398.

Hayden, Brian

1981 Subsistence and ecological adaptations of modern hunter/gatherers. In Omniv orous primates: Gathering and hunting in human evolution, edited by R. S. O. Harding and G. Teleki, pp. 344-421. Columbia Univ. Press, New York.

Haynes, C. V.

1970 Geochronology of man-mammoth sites and their bearing on the origin of the Llano complex. In Pleistocene and recent environments of the central Great Plains, edited by W. W. Dort and A. E. Johnson, pp. 77-92. Special Publication 3. University of Kansas, Lawrence.

1982 Were Clovis progenitors in Beringia? In Paleoecology of Beringia, edited by David M. Hopkins, John V. Matthews, Jr., Charles E. Schweger, and Steven B. Young, pp. 383-398. Academic Press, New York.

Hibbert, D.

1982 History of the steppe-tundra concept. In Paleoecology of Beringia, edited by David M. Hopkins, John V. Matthews, Jr., Charles E. Schweger, and Steven B. Young, pp. 153-156. Academic Press, New York.

Hill, M. W.

1948 The atlatl or throwing stick: A recent study of atlatls in use with darts of various sizes. Tennessee Archaeological Society 4:37-44.

Howell, Nancy

1976 The population of the Dobe area !Kung. In Kalahari hunter-gatherers: Studies 
of the !Kung San and their neighbors, edited by Richard B. Lee and Irven DeVore, pp. 137-151. Harvard Univ. Press, Cambridge.

1979 Demography of the Dobe !Kung. Academic Press, New York.

Huckell, Bruce B.

1979 Of chipped stone tools, elephants, and the Clovis hunters: An experiment. Plains Anthropologist 24:177-189.

Jennings, Jesse D.

1983 Origins. In Ancient North Americans, edited by Jesse D. Jennings, pp. 25-67. Freeman, San Francisco.

Kellar, J. H.

1955 The atlatl in North America. Indiana Historical Society, Prehistory Research Series, III, No. 3:281-352.

Kleindienst, Maxine R., and Charles M. Keller

1975 Towards a functional analysis of handaxes and cleavers: The evidence from eastern Africa. Man (N.S.) II:176-187.

Lahren, L., and R. Bonnichsen

1974 Bone foreshafts from a Clovis burial in southwestern Montana. Science 186:147150 .

Lee, Richard B.

1979 The !Kung San: Men, women and work in a foraging society. Cambridge Univ. Press, Cambridge.

Leith, $\mathrm{H}$.

1975 Modeling the primary productivity of the world. In Primary productivity of the biosphere. Ecological Studies 14, edited by H. Leith and Robert H. Whittaker,

Lewin, Richard pp. 237-263. Springer-Verlag, New York.

1987 The first Americans are getting younger. Science 238:1230-1232.

Lynch, Thomas F.

1978 The South American Paleo-Indians. In Ancient Native Americans, edited by Jesse D. Jennings, pp. 455-489. Freeman, San Francisco.

1983 The Paleo-Indians. In Ancient South Americans, edited by Jesse D. Jennings, pp. 87-137. Freeman, San Francisco.

MacArthur, Robert H., and Eric R. Pianka

1966 On optimal use of a patchy environment. The American Naturalist 100:603-609.

Martin, Paul S.

1966 Africa and Pleistocene overkill. Nature (London) 212:339-342.

1967 Prehistoric overkill. In Pleistocene extinctions: The search for a cause, edited by Paul S. Martin and H. E. Wright, Jr., pp. 75-120. Yale Univ. Press, New Haven.

1973 The discovery of America. Science 179:969-974.

1982 The pattern and meaning of Holarctic mammoth extinction. In Paleoecology of Beringia, edited by David M. Hopkins, John V. Matthews, Jr., Charles E. Schweger, and Steven B. Young, pp. 399-408. Academic Press, New York.

1984 Prehistoric overkill: The global model. In Quaternary extinctions: A prehistoric revolution, edited by Paul S. Martin and Richard C. Klein, pp. 354-403. Univ. of Arizona Press, Tucson.

May, Robert M

1973 Stability and complexity in model ecosystems. Monographs in Population Biology No. 6. Princeton Univ. Press, Princeton, NJ.

McDonald, Jerry N.

1984 The reordered North American selection regime and late Quaternary megafau- 
nal extinctions. In Quaternary extinctions: A prehistoric revolution, edited by Paul S. Martin, and Richard C. Klein, pp. 404-439. Univ. of Arizona Press, Tucson.

McNaughton, S. J., and Larry L. Wolf

1973 General ecology. Holt, Rinehart and Winston, New York.

Minnis, Paul E.

1985 Social adaptation to food stress: A prehistoric southwestern example. Univ. of Chicago Press, Chicago.

Mosimann, James E., and Paul S. Martin

1975 Simulating overkill by Paleoindians. American Scientist 63:304-313.

Oswalt, Wendel $\mathrm{H}$.

1979 An anthropological analysis of food getting technology. Willey-Interscience, New York.

Owen-Smith, Norman

1987 Pleistocene extinctions: The pivotal role of megaherbivores. Paleobiology 13:351-362.

Peets, Orville $\mathrm{H}$.

1960 Experiments in the use of atlatl weights. American Antiquity 26:108-110.

Redmann, R. E.

1982 Production and diversity in contemporary grasslands. In Paleoecology of Beringia, edited by David M. Hopkins, John V. Matthews, Jr., Charles E.

Schoener, T. W.

Schweger, and Steven B. Young, pp. 223-239. Academic Press, New York.

1969a Models of optimal size for solitary predators. American Naturalist 103:277-313.

1969b Optimal size and specialization in constant and fluctuating environments: An energy-time approach. Brookhaven Symposium Biology 22:103-114.

1971 Theory of feeding strategies. Annual Review of Ecology and Systematics 2:369 404.

1973 Population growth regulated by intraspecific competition for energy or time: Some simple representations. Theoretical Population Biology 4:56-84.

1987 A brief history of optimal foraging ecology. In Foraging behavior, edited by Alan C. Kamil, John R. Krebs, and H. Ronald Pulliam, pp. 5-67. Plenum, New York.

Schweger, C. E.

1982 Primary production and the Pleistocene ungulates: the productivity paradox. In Paleoecology of Beringia, edited by David M. Hopkins, John V. Matthews, Jr., Charles E. Schweger, and Steven B. Young, pp. 219-221. Academic Press, New York.

Stanford, D., R. Bonnichsen, and R. E. Morlan

1981 The Ginsberg experiment: Modern and prehistoric evidence of a bone-flaking technology. Science 212:438-440.

Stephens, David W., and John R. Krebs

1986 Foraging theory. Monographs in Behavioral Ecology. Princeton Univ. Press, Princeton, NJ.

Tanner, Nancy Makepeace

1981 On becoming human. Cambridge Univ. Press, Cambridge.

Vickers, W. T.

1988 Game depletion hypothesis of Amazonian adaptation: Data from a native community. Science 239:1521-1522.

Webster, David

1981 Late Pleistocene extinction and human predation: A critical overview. In Om- 
nivorous primates: Gathering and hunting in human evolution, edited by R. S. O. Harding and G. Teleki, pp. 556-594. Columbia Univ. Press, New York. Webster, David, and Gary Webster

1984 Optimal hunting and Pleistocene extinction. Human Ecology 12:275-289.

Werner, Earl E.

1977 Species packing and niche complementarity in three sunfishes. American Naturalist 111:553-578.

Wesler, Kit W.

1981 Models for Pleistocene extinction. North American Archaeologist 2:85-100.

Whittaker, Robert

1970 Communities and ecosystems. MacMillan, New York.

Whittington, Stephen L., and Bennett Dyke

1984 Simulating overkill: Experiments with the Mosimann and Martin model. In Quaternary extinctions: A prehistoric revolution, edited by Paul S. Martin and Richard C. Klein, pp. 451-465. Univ. of Arizona Press, Tucson.

Winterhalder, Bruce, W. Baillargeon, F. Cappelletto, I. R. Daniel, Jr., and C. Prescott

1988 The population ecology of hunter-gatherers and their prey. Journal of Anthropological Archaeology 7:

Wobst, H. Martin

1974 Boundary conditions for Paleolithic social systems: A simulation approach. American Antiquity 39:147-178. 